\title{
THE TOHOKU DISASTERS: CHIEF LESSONS CONCERNING THE POST DISASTER HUMANITARIAN LOGISTICS RESPONSE AND POLICY IMPLICATIONS
}

José Holguín-Veras, Ph.D., P.E.

William H. Hart Professor, Director of the Center for Infrastructure, Transportation, and the Environment and the VREF Center of Excellence for Sustainable Urban Freight Systems

Civil and Environmental Engineering

Rensselaer Polytechnic Institute, $1108^{\text {th }}$ St, Room JEC 4030, NY Troy, USA, ZIP 12180

Phone: +1 518-276-6221_Email: jhv@rpi.edu

Eiichi Taniguchi, Ph.D.

Department of Urban Management

Kyoto University, Katsura Campus, Nishikyo-ku, Kyoto 615-8540 Japan

Phone: +81-75-383-3229Ｅmail: taniguchi@kiban.kuciv.kyoto-u.ac.jp

Miguel Jaller, Ph.D.

Civil and Environmental Engineering

Rensselaer Polytechnic Institute, $1108^{\text {th }}$ St, Room JEC 4030, NY Troy, USA, ZIP 12180

Phone: +1 518-276-6221Ｅmail: jallem@rpi.edu

Felipe Aros-Vera, M.Sc.

Civil and Environmental Engineering

Rensselaer Polytechnic Institute, $1108^{\text {th }}$ St, Room JEC 4030, NY Troy, USA, ZIP 12180

Phone: +1 518-276-6221_Email: arosvm@rpi.edu

Frederico Ferreira, Ph.D.

Department of Urban Management

Unit for Liveable Cities

Kyoto University, Katsura Campus, Nishikyo-ku, Kyoto 615-8540 Japan

Phone:+81-75-383-2819_Email:drfred.ferreira@gmail.com

Russell G. Thompson, Ph.D.

Institute of Transport Studies

Monash University

Clayton, Australia 3800

Phone: +61499051850Ｅmail: russell.thompson@monash.edu

\begin{abstract}
This paper describes the findings of the research conducted by the authors on the humanitarian logistic efforts after the cascading disasters that impacted the Tohoku region after the Great East Japan Earthquake of March $11^{\text {th }}$, 2011. Using a combination of in depth interviews with participants in the relief efforts and meta analyses of news accounts, the authors identified lessons learned by the participants, and the corresponding policy implications and suggestions for improvement of future response efforts.
\end{abstract}




\section{INTRODUCTION}

The extreme nature of disasters poses significant challenges to the individuals and organizations involved in the delivery of critical supplies to assist the people in need. This is because: (1) the social networks that orchestrate the array of technical activities concerning logistics are severely disrupted or destroyed; (2) the infrastructure and communication systems that support such socio-technical process of logistics may have been impacted and unable to fully function; (3) there is a great deal of uncertainty about infrastructure conditions; (4) large (and dynamic) volumes of critical supplies must be transported; (5) there is a short timeframe to respond and prevent loss of lives and property; (6) there is a huge amount of uncertainty about what is actually needed, where is needed, and what is available at the site; (7) the ability of the local leaders, civil society, and private sector to organize an effective response may have been compromised by the event itself; (8) large proportions of critical local assets such as trucks and supplies may have been destroyed, thus preventing their use as a first wave of relief aid; and, (9) the event generates a huge flow of donations with large proportions of supplies that are not needed at the site, which complicates the response tremendously as handling these goods detract resources from other more important tasks (Holguín-Veras et al., 2007; Holguín-Veras et al., 2012b). These characteristics set postdisaster humanitarian logistics (PD-HL) apart from both commercial logistics and the various forms of longer term humanitarian logistic endeavors-termed regular humanitarian logistics in Holguín-Veras et al. (2012b) — such as distribution of medicine and/or food in crisis regions, that take place in less chaotic environments. In this context, PD-HL is very different than its commercial and the regular humanitarian logistic counterpart, in terms of: (1) objectives pursued; (2) nature and origination of the commodity flows transported, (3) knowledge of demand, (4) decision making structure, (5) periodicity / volume of logistic activities, and (6) state of the supporting systems, e.g., transportation and communications, (Holguín-Veras et al., 2010; Holguín-Veras et al., 2012b).

A major issue that hampers research, development, and implementation of more effective PD-HL systems is that the realities of actual operations are poorly understood. The reasons for this situation are three-fold: (1) the relatively low occurrence of large disasters and catastrophic events; (2) the small size of the professional and research PD-HL communities; and, (3) the transient involvement of responders and the dynamic nature of the operations and data. To start with, large scale disasters are rare events that, even in disaster-prone countries like Japan, happen many years apart and typically impact different jurisdictions. Thus, only a relatively small number of individuals get involved in more than one large disaster, which prevents the accumulation of experiences that is central to knowledge creation. In Japan, for instance, the last major disaster before the one of March 11 ${ }^{\text {th }}$, 2011 was the 1995 Kobe earthquake. After the sixteen years that elapsed between the Kobe and Tohoku disasters, it is likely that the bulk of the individuals involved in the Kobe response either moved to other pursuits, or retired.

A second important reason is the minuscule number of individuals involved in PD-HL on a regular basis. In contrast to other disciplines (e.g., medical response, search and rescue) in which tens and even hundreds of thousands of individuals perform and train on these duties on a daily basis, the number of people routinely working on PD-HL is very small. The reason is that only large disasters and catastrophic events - which as said are few and far between - require sophisticated PD-HL operations (Holguín-Veras et al., 2012b). It is entirely possible that less than five hundred individuals, worldwide, work full time on

PD-HL. Complicating the matter, these highly qualified professionals are not inclined to write 
publications that could help create a knowledge base on PD-HL. If and when they write documents discussing PD-HL, these are typically internal (agency) reports of restricted circulation.

The small number of full-time PD-HL professionals leads to a situation where if not by the voluntary and emergent participation of hundreds and thousands of individuals that take over the HL efforts, these operations would come to a halt. The downside is that the vast majority of these individuals have no previous experience in these matters. Not surprisingly, none of the about 60 individuals interviewed for the paper had PD-HL experience, and only about 10 had experience in commercial logistics. The vast majority of the responders, as one of them put it "...had no idea about what a distribution center is...” (Holguín-Veras et al., 2011b).

The third reason is the ephemeral nature of the data. Disaster response is a transient and highly dynamic activity with markedly different phases, ranging from a chaotic initial phase in which the main goal is to assess conditions and define a path for the stabilization of the crisis; to much calmer phases of expansion and consolidation during which the focus is on how to meet the needs in an efficient manner. The dynamic nature of the activity, together with the fast rotation of the staff and volunteers involved in the work, poses a major challenge for characterizing and understanding PD-HL operations. International relief agencies, for instance, typically send their top staffers at the onset of the crisis so that they, on account of their experience, stabilize the situation. Once this is achieved, the top teams are rotated out to give them some rest, and are replaced by follow up teams that take care of the process for another period of time (at some point these teams are also rotated out.) Similarly, volunteers and local responders tend to switch out of the response as time passes on as they have to return to their regular activities, or simply need time to recover. The net result is that the individuals doing PD-HL weeks after the disaster are not likely to be the same ones that responded in the initial days and, for that reason, cannot provide full accounts of what transpired at the beginning of the crisis. Thus, there is a very limited amount of time to identify and interview the individuals involved in the crucial initial phases, and gather the data they could share about it. If the researchers fail to arrive soon enough, or if they do not manage to get access to the proper individual(s), or if they are not allowed to observe the operations, the opportunity to characterize and collect data about the initial stages gets increasingly difficult as time passes on. At some point it is no longer possible to document the operations as memories fade, data are lost, and the ability to identify and find the individuals involved evaporates. These factors lead to a situation in which the level of knowledge about PD-HL possessed by outsiders to the response is very small. Not surprisingly, only a handful of the PD-HL cases have been systematically studied (e.g., Katrina, Haiti, Thailand), and only a handful of publications (Russell, 2005; Holguín-Veras et al., 2007; Tabbara, 2008; Beresford and Pettit, 2009; Holguín-Veras et al., 2012a) discuss PD-HL based on direct observations. In general, the bulk of publications focus on the application of management theory or operations research to HL operations. For comprehensive reviews of the literature, see Altay and Green (2006), Kovacs and Spens (2007), and Galindo and Batta (2013). The research community has only scratched the surface of this subject.

This paper is important because it provides evidence-based insight into actual PD-HL practices, and the lessons that ought to be learned to improve plans and response procedures. Since solid knowledge of PDHL practices is a requirement for the development of policies, decision support tools, and analytical models aimed at improve PD-HL, field research like the one reported here is key to develop new paradigms of PD-HL able to deal with the real life complexity of the operations. In essence, it is difficult to improve the operations of a system that is poorly understood. This topic has long been identified as a 
key priority by the Federal Emergency Management Agency (FEMA), that stressed the need to “...improve the distribution of critical assets and goods in a catastrophic event..." (Picciano, 2002).

The fundamental objectives of this paper are to: (1) identify how the unique nature of the cascading disasters in the Tohoku region impacted the PD-HL response; (2) characterize the PD-HL operations implemented to respond to the Tohoku disasters; (3) assess how the persistent nuclear threat impacted the overall PD-HL effort; (4) document lessons learned, both positive and negative; (5) identify the factors that explain the contrasting performances of construction and PD-HL operations; and (6) identify a set of policy recommendations to improve future disaster response. It is important to highlight that the focus is on how to enhance the efficiency of the entire disaster response, as opposed to a single relief group.

The paper has six sections in addition to this introduction. Section 2 briefly describes the methodology used in this research. Section 3 discusses the cascading disasters that precipitated the humanitarian crisis in Tohoku. Section 4 provides a system-level overview of disaster preparedness and PD-HL response efforts. Section 5 analyzes the lessons learned by the interviewees. Section 6 identifies policy implications and a set of recommendations to improve future disaster response efforts. Section 7 conducts a comparative analysis of the contrasting performances of the construction work and PD-HL. Section 8 summarizes the chief findings of the work.

\section{METHODOLOGY}

The paper summarizes the work of an international team that, with funding from the National Science Foundation and the Japanese Science and Technology Agency, visited the Tohoku region. The data were collected using a multi-prong approach based on in depth interviews with the key participants in the relief efforts, assembly of a comprehensive database of news articles and reports, and the creation of a timeline of relevant events. The interviews, conducted during several trips to the area, were with the Tohoku Regional Bureau of the Ministry of Land, Infrastructure, Transport, and Tourism (MLIT); the prefectures of Miyagi, Iwate, and Fukushima; the cities of Ishinomaki and Kesennuma, and three large private companies (i.e., Yamato, Sagawa, and AEON), that were involved in the response. In all cases, the authors met with numerous staff members.

The methodology used by the authors followed standard practices of disaster field research that relies on a dynamic process based on interviews with disaster responders, documentation of the conditions prevailing during the response, identifications of lessons learned, and analyses of results. For an overview, see Holguín-Veras et al. (2013b). Typical of post-disaster environments, the research has to contend with numerous challenges: the individuals involved in the response constantly change, their memories fade; interviewees may fear retribution if they disclose information considered critical of some aspect of the response, or may feel compelled to convey an idealized or sanitized version of what actually happened; records are poorly kept or not kept at all, and whatever data are kept are difficult to get. For these reasons, the fieldwork heavily relies on interviews, analyses of media accounts, and the use of quantitative techniques to corroborate findings, and produce an objective account of the operations.

The interviews are based on a set of pre-defined protocols, already pre-approved by the Institutional Review Board, which have been used by the authors in multiple disasters (e.g., Katrina, the Joplin tornado, the Alabama tornadoes, Haiti, Super Storm Sandy). The interview protocol is intended to provide a guide to the in-depth-interview, not as a formal questionnaire to be answered. It includes questions to assess the respondents' level of familiarity with PD-HL, nature of the involvement in the effort, obstacles 
faced, lessons learned, nature of the supplies delivered, among others. The protocol is designed to be flexible and open ended so that it accommodates a wide range of responses, and has been continuously improved since it was first developed as part of the fieldwork conducted after Hurricane Katrina (Holguín-Veras et al., 2007).

As a matter of policy, the authors try to interview a sample of the individuals that have been directly involved, and impacted by, the PD-HL efforts. An effort is made to reach the disaster site as soon as the team has arranged for suitable local support, travel, and enough supplies to meet the needs of team members for a meaningful amount of time. Cognizant of the fact that different individuals may have different views of the operations, which tend to depend on their position in the response, the authors always attempt to interview individuals that represent the key institutions and sectors of the civic society: all layers of government (national, state, city, local), community leaders (religious, secular), international relief agencies and groups, non-governmental organizations (NGOs), and private sector companies. The interviews are recorded with the consent of participants, transcribed if needed; and analyzed to extract insight to help explain why the response evolved in the way it did, and identify the key lessons that should be learned to improve future disaster response. To ensure anonymity, the names of the individuals that provided the information are not disclosed. In the case of Japan, most of the interviews were attended by groups of individuals that complemented the information provided by the lead interviewee. In terms of composition, fifty participants were either public sector or volunteers collaborating with the public sector, while ten were staff from the private companies. Cross validation of responses is used to mitigate the limitations inherent in relying on accounts and information provided by individuals that, for the most part, only had a partial view of the operations.

In parallel to the fieldwork and interviews, immediately after the onset of the disaster, a vigorous and comprehensive media focused data collection program is activated. Multiple media feeds from newspapers, television, Internet blogs, and electronic social media feeds are collected, downloaded, catalogued, and coded. The massive amount of the data collected through these means is synthesized to help develop timelines of the key events, and a basic script that describes how the response evolved.

Throughout the paper, the supplies that arrived to the disaster area are classified using the levels of priority defined by the Pan-American Health Organization, PAHO, (Pan American Health Organization, 2001). This classification system divides supplies in three groups: high-priority, which are goods urgently needed at the site; low-priority, which are those that could be needed later on and must be stored for future use; and, non-priority items that are those that are not needed, not appropriate to the needs, or that could do harm if distributed to the survivors. Throughout the paper, metric units are used.

\section{THE CASCADING DISASTERS}

On March $11^{\text {th }}$, 2011 a 9.0 earthquake struck $130 \mathrm{~km}$ East of the city of Sendai in the East Coast of the Island of Honshu, Japan. Lasting about five minutes, the earthquake-referred to as the "Great East Japan Earthquake"-produced a violent shaking and unusual duration that damaged an untold number of roads and buildings. Providing testimony of Japan's seismic design and construction practices, physical damage was kept to a minimum; and loss of lives by the earthquake was relatively low considering its intensity. However, the earthquake led to the temporary shutdown of ports, airports, subways, and rail systems throughout Japan (Journal of Commerce, 2011d). 
Immediately after the earthquake, tsunami alerts were issued throughout the Japanese East coast. The warnings predicted waves of 6-7 $\mathrm{m}$ height which, in most cases, would have been within the design range of the tsunami protection infrastructure. Scores of local citizens, well trained after years of emergency drills, moved to higher ground following pre-established tsunami evacuation routes. In a notable example, the residents of the small fishing village of Murohama - who did not receive any warning because the tsunami warning tower had been destroyed by the earthquake-followed the teaching of their ancestors and were spared (Holguín Veras, 2012). Regrettably, anecdotal evidence suggests that many individuals - with fresh memories of the false alarms of February $22^{\text {nd }}$ and March $9^{\text {th }}$, 2011 (with a magnitude of 7.3) earthquakes-ignored the warnings. As expected, the waves struck the Eastern seaboard of Japan. Unfortunately, the waves were much higher than anticipated as tens of cities and villages, and hundreds of small communities were hit by waves towering in excess of 12-16 $\mathrm{m}$, with a reported maximum of $39 \mathrm{~m}$ in Northern Japan (NHK World News, 2011b). There was also confusion about the arrival time of the tsunami waves, which may have led people to believe that the danger had passed when in fact, the tsunami was still on its way (NHK World News, 2011b).

The Japanese people had been preparing for such a scenario for decades. Local governments had organized tens of thousands of evacuation drills throughout the country and invested heavily on seismic resistant structures and tsunami protection infrastructure and systems. The latter includes a huge network of tidal gauges to collect real time wave height data, sophisticated computer systems that process the wave height data and issue automatic warnings in case of danger, and an estimated 8,800 miles of seawalls and breakwaters to protect life and property (New York Times, 2011a).

In the Tohoku region - the one closest to the epicenter and the one most heavily impacted - the most critical pieces of infrastructure are the: Sendai Airport, Iwate-Hanamaki Airport, Port of SendaiShiogama, Port of Onahama, Tohoku Motorway, Joban Motorway, Sanriku Motorway, Routes 4, 6, and 45, the East-West arterials connecting the Tohoku Motorway to the coastal areas, the Tohoku Shinkansen (high-speed railway), the Fukushima Daiichi Nuclear Plant, and the Onagawa Nuclear Plant (Journal of Commerce, 2011l). In addition, there are hundreds of miles of populated areas where agriculture, industrial activity, and human habitation take place. Figure 1 shows the key infrastructure in Tohoku.

Overall, the level of protection against tsunamis was uneven. In most of the populated areas, seawallsnot as effective as breakwaters and certainly much less effective than tsunami breakwaters-were the main form of protection. The Sendai airport, located about one $\mathrm{km}$ from the coast behind a $4 \mathrm{~m}$ seawall, was deemed to be in a safe area (NHK World News, 2011b). The Fukushima Daiichi Nuclear complex had a double layer of protection as the reactors had been located at the top of a $6 \mathrm{~m}$ bluff facing the sea, and a small two-wing breakwater protected the facilities. In contrast, the Port of Sendai has two sets of breakwaters including a massive deep water tsunami breakwater located $3 \mathrm{~km}$ from the port. These critical facilities experienced different levels of damage. The airport, though flooded, did not experience irreparable damage, and was back in operation six days after the disaster (Washington Post, 2011c). The port was in acceptable shape, though hundreds of containers were piled up by the waves requiring significant clean-up. More importantly, the piers were not damaged though gantry (ship) cranes needed repairs (a very different situation than what happened in Port au Prince, where both piers and cranes were completely destroyed by the earthquake, thus removing a crucial component of the logistic system). The port was opened to receive relief supplies on March $18^{\text {th }}$ (Journal of Commerce, 2011r), to commercial domestic traffic on March $29^{\text {th }}$ (Journal of Commerce, 2011l), and to international containers on June $9^{\text {th }}$, 2011 (Journal of Commerce, 2011c). 
Farther away from the epicenter, the Fukushima Daiichi nuclear complex did survive the earthquake, and went into the automatic shutdown established in emergency procedures. Unfortunately, the tsunami waves overtopped both the breakwater and the bluff, flooding the emergency generators that provided the electricity to run the water pumps needed to cool the nuclear reactors. The crisis that followed-that culminated with the release of radioactive material-impacted the response in rather dramatic ways as it deterred the convergence of volunteers and materials to the disaster site. As a result, local responders had to undertake the response without the assistance of the massive help that typically comes from the outside bringing manpower, equipment, supplies, and expertise. The deterrent effect that the nuclear crisis had on both people and material convergence sets the Tohoku disasters apart from the most recent events (one would need to go back to Chernobyl to find a precedent); as in most disasters once the physical phenomenon that produced them fades away, the response can start in earnest.

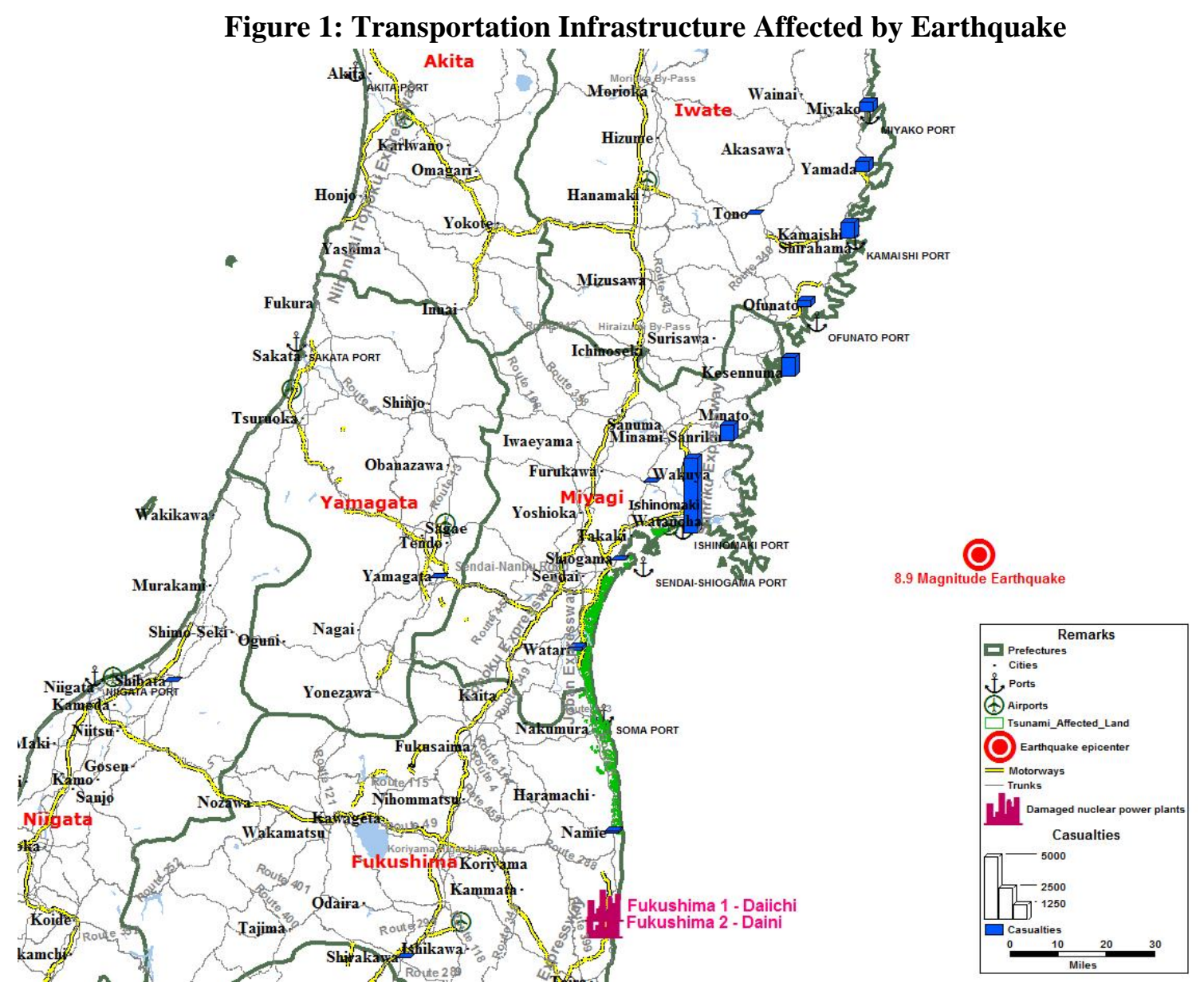

Three specific features make the Tohoku disaster an event without precedents in recorded disaster history: (1) severity and pervasiveness of the danger, (2) geographic coverage with both widespread and localized damage, and (3) persistence over time. In terms of severity, the earthquake and tsunami are among the strongest on record, while the nuclear crisis is only topped by Chernobyl. Adding to the complexity, the pervasiveness of the (invisible) nuclear threat-and the fact that it conjures images from Hiroshima, Nagasaki, and Chernobyl—sent a powerful deterring signal to potential responders outside the area. The disasters also impacted a large geographic area: the tsunami wiped out hundreds of square kilometers of coastal communities, while the nuclear crisis threatened the health of individuals and 
impacted environmental conditions within a large radius from the nuclear plants. A unique feature of the disasters was that the damage was both widespread and localized. It was widespread because it impacted large continuous urban areas, e.g., Ishinomaki, and it was localized as it destroyed numerous isolated communities leaving untouched communities nearby that were not on the path of the tsunami. Finally, the time-persistence of the nuclear crisis - which lasted months - and its impacts on the response may ultimately be the defining factor as it profoundly altered the flows of goods and the very essence of the PD-HL process, particularly in the Fukushima Prefecture.

Important to the purposes of this paper is that for some communities (e.g., Ishinomaki, Minami Sanriku) the Tohoku disaster was a catastrophic event, because: “...most or all of the community built structure is heavily impacted... [and] facilities and operational bases of most emergency organizations are themselves usually hit...”; “...local officials are unable to undertake their usual work role...”; “...help from nearby communities cannot be provided...”; “...most, if not all, of the everyday community functions are sharply and concurrently interrupted...”; “...the mass media system especially in recent times socially constructs catastrophes even more than they do disasters...”; “...mass out-migrations for protracted periods of time...”; and, because of the previous processes “..., the political arena becomes even more important...” (Quarantelli, 2006; Wachtendorf et al., 2010). As discussed in Holguín-Veras et al. (2012b), the catastrophic nature of the event has a profound and dramatic impact on PD-HL because of a number of interrelated effects. First and foremost, logistic activity is a socio-technical process in which a social network of individuals (e.g., shippers, carriers, receivers) organize technical activities such as routing and distribution, using supporting systems, e.g., transportation and communications. In this context, events that impact any of these components could produce massive disruption in this socio-technical process. Second, large portions (and, in some cases, all) of the inventories of supplies held by households and businesses in the impacted area are destroyed, which deprives the local communities of what otherwise would be readily available critical supplies. Third, the private sector supply chains that-in normal conditions bring all the supplies needed by the community—are severely disrupted (taking them weeks to recover) or completely destroyed. Fourth, the demand for supplies at the disaster area increases tremendously due to the combined needs of: survivors, the response process itself, and local stores that perceiving a business opportunity due to precautionary/opportunistic buying on the part of individual (mostly from the outside of the disaster area) increase the size of their purchases above and beyond what is actually needed under normal conditions. The combined impacts on supply and demand leads to a situation in which the only practical alternative is to bring the supplies from the outside. This stands in contrast with smaller disasters where local inventories and the existing private sector supply chains are able to satisfy most of the immediate needs of survivors. The failure to recognize this crucial difference, and prepare for it, had major impacts on the response as discussed next.

\section{OVERVIEW OF PREPAREDNESS AND RESPONSE EFFORTS}

This section provides a general overview of both disaster preparedness and the response. In all cases, the discussions center on the PD-HL effort as other important aspects (e.g., search and rescue, medical logistics) are outside the scope of the paper.

\subsection{Overview of disaster preparedness efforts}

The public sector interviewees reported having taken numerous steps to enhance disaster response as prefectures and cities had response plans that outlined the actions they would take in case of a disaster. 
However, all of them reported that these plans were not followed, for the simple reason that they only considered a small disaster and not a catastrophe as the one they faced. Moreover, the respondents indicated that — with perfect hindsight—PD-HL was not adequately discussed in the response plans: in some cases it was not mentioned at all; in another "...it was just one line in the plan..." (Iwate Prefecture), and in three cases (Miyagi, Iwate, and Fukushima prefectures) was limited to identifying a handful of distribution centers or DCs, (Holguín-Veras et al., 2011d; Holguín-Veras et al., 2011b; Taniguchi et al., 2011a; Taniguchi et al., 2011c; Taniguchi et al., 2011b). Quite tellingly, none of the plans considered in adequate detail the local distribution, and how the manpower and assets required for the entire operation would be secured. In the words of a company staffer: “...they were assuming that 'somebody else’ would take care of the distribution of relief supplies...” (Holguín-Veras et al., 2011a).

Not surprisingly, PD-HL did not figure prominently in the training exercises annually conducted by local governments. The respondents could only recall two cases (Fukushima Prefecture and Ishinomaki City) with a PD-HL component, albeit small ones. In one of them, the staff transported supplies from the outside of the region to a DC inside the area. The other involved transporting cargo from a shopping mall to a single Refuge Center (RC), which was deemed by participants as “...simplistic...”. Reflecting on the experience that they went through, a staff member at Fukushima Prefecture indicated that “...a quality exercise would have been very helpful...” (Taniguchi et al., 2011b). The lack of complex and realistic exercises involving local distribution prevented the agencies from appreciating the complexity associated with the challenge they would face in March $11^{\text {th }}$, 2011.

In their favor, most of the agencies and local governments had signed cooperation agreements with potential private sector partners. In the case of the MLIT, the agreements were with construction companies for debris removal and construction work (Taniguchi et al., 2011d). In the case of prefectures and cities, the typical agreement was with the Japanese Trucking Association (JTA) for the transportation of supplies from the outside of the disaster area to the DCs operated by these governments. In addition, some prefectures, e.g., Miyagi, had signed agreements with construction companies. Unanimously, the transportation agreements were deemed “...too general...” by interviewees (Holguín-Veras et al., 2011a; Holguín-Veras et al., 2011d; Taniguchi et al., 2011a; Taniguchi et al., 2011b) as they did not specify crucial details such as who would organize the local population, who will be the public sector person in charge of PD-HL, where the RCs would be located, how many people would be expected at each RC, who would be in charge of the local distribution of the relief aid, how much and what type of cargo would be transported, among other key operational details. Not recognizing the complexity and magnitude of the challenge associated with local distribution would have dramatic consequences. Moreover, the lack of established relationships between government authorities and transport and logistics companiesparticularly local ones-hindered an efficient response. Only the Fukushima Prefecture had an agreement with a local trucking organization (Taniguchi et al., 2011b), which seems to have worked well as the local truckers assumed from the start (though it was not explicit in the agreement) that they would take care of the local distribution. This agreement with local truckers provided the prefecture with speedy access to local assets and knowhow where, and when, relief supplies were needed the most.

In terms of the structure of the PD-HL networks, the disaster plans typically defined a three echelon network with the DCs managed by the prefectures at the top, a middle layer with DCs operated by the cities, and Refuge Centers (RCs) at the bottom (see Figure 2). Implicit in this structure was the assumption that the cities would be able to undertake the PD-HL work at their DCs and RCs; and that, as a result, the role of the prefectures would be to ensure a suitable flow of supplies from their DCs to the 
DCs operated by the cities. Unfortunately, such assumption was wrong as the ability of the cities (which have been destroyed by the tsunami) to man, organize, and orchestrate the operations at DCs and RCs had been obliterated by the tsumani. This, in turn, forced the prefectures to undertake major components of the local distribution, which was a task for which they were not prepared, nor they had the physical resources required to do a good job. In the chaos that ensued, supplies went directly to improvised DCs and in some cases to the RCs, making difficult to coordinate deliveries and conduct any form of centralized management and control. Over time, the system evolved towards a structure in which some of the DCs operated as warehouses of non/low-priority supplies; while others operated as DCs. Thus, depending on their cargo the vehicles were sent to one or the other. In other cases, non/low-priority supplies were allowed to unload at the busiest DCs complicating operations there as these locations were already congested, and had limited manpower to unload, sort, store, and manage such cargo.

Figure 2: Schematic of Flow of Supplies as Defined in Disaster Plans

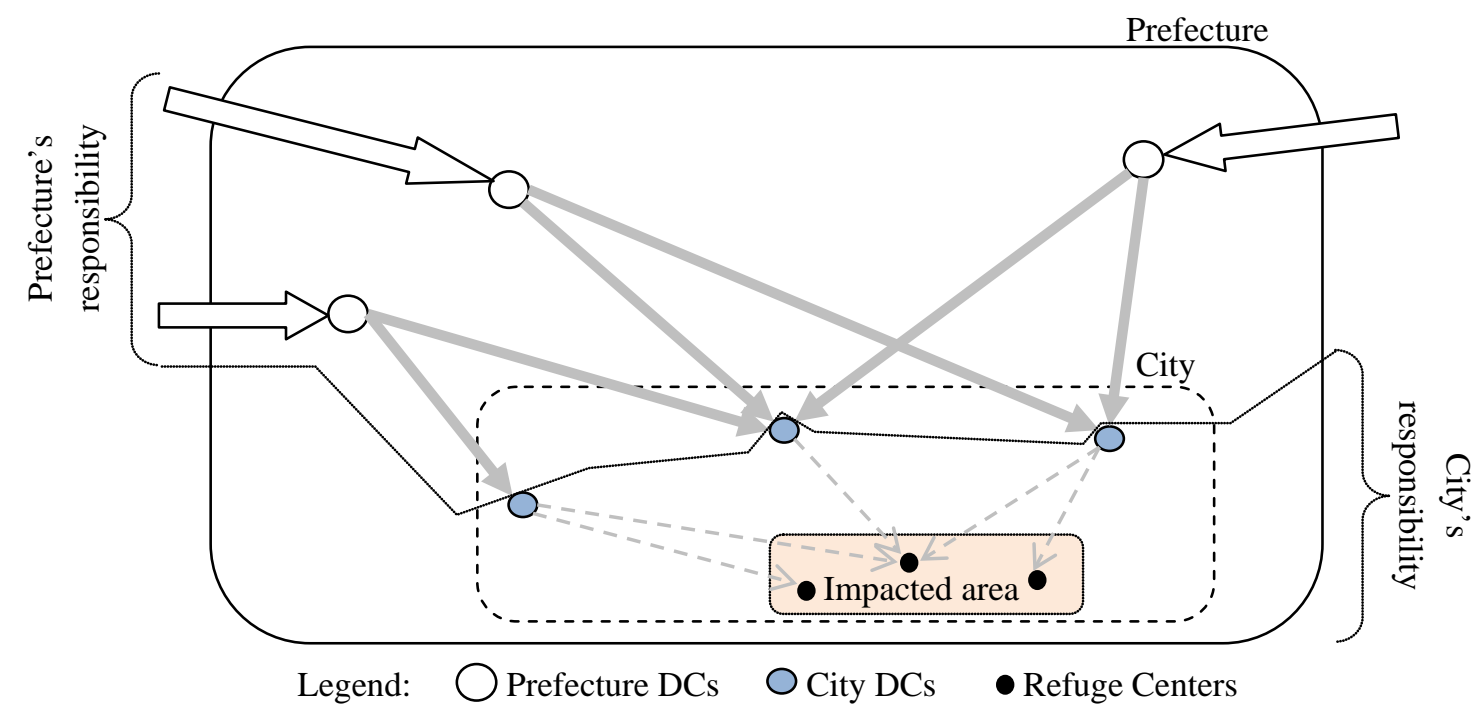

All the prefectures (i.e., Miyagi, Iwate, and Fukushima) and one city (Ishinomaki) indicated that they had prepositioned critical supplies (e.g., blankets, meals ready to eat, water) though all considered the prepositioned amounts “...were not enough...” which would come to haunt them (Holguín-Veras et al., 2011d; Taniguchi et al., 2011c). The companies interviewed had inventories of food, water, and other supplies-intended for their normal business operations-which were used during the immediate response (Holguín-Veras et al., 2011a). The companies also had contingency plans to deal with minor emergencies and interruptions, such as a blackout of limited duration.

\subsection{Overview of the disaster response}

This section discusses the most salient events concerning the PD-HL response to the Tohoku disasters. To facilitate understanding of the complex response that followed, a timeline with milestones is shown in Table 1. The most striking aspects of the table are the breadth of the impacts on all modes of transportation both in and outside the disaster area; and the time persistent effects produced by the nuclear crisis, which hampered the response for an extended period of time.

Table 1: Timeline of events concerning PD-HL

\begin{tabular}{|l|l|l|}
\hline Date & Description & Source \\
\hline 3/11/2011 & Great East Japan Earthquake and tsunami & (Journal of Commerce, 2011d) \\
\hline
\end{tabular}




\begin{tabular}{|c|c|c|}
\hline & Ports, airports, highways shutdown & (Journal of Commerce, 2011d) \\
\hline & Container shipping traffic stopped & (Journal of Commerce, 2011m) \\
\hline & Train service suspended in Tokyo & (NHK World News, 2011a) \\
\hline \multirow[t]{4}{*}{$3 / 12 / 2011$} & Tokyo trains to resume service & (NHK World News, 2011c) \\
\hline & Japanese government sends aircraft and ships & (Washington Post, 2011b) \\
\hline & 11 out 16 East-West arterials opened & (MLIT, 2011) \\
\hline & Prefectures start receiving supplies & (Taniguchi et al., 2011a) \\
\hline \multirow[t]{2}{*}{$3 / 13 / 2011$} & SDF ready to mobilize 50,000 troops & (Kyodo News, 2011b) \\
\hline & Nine expressways close, hundreds of flights canceled & (Kyodo News, 2011b) \\
\hline $3 / 14 / 2011$ & Ports of Tokyo, Yokohama; Tokyo airports open & (Journal of Commerce, 2011j) \\
\hline \multirow[t]{3}{*}{$3 / 15 / 2011$} & Lack of relief supplies reported & (Washington Post, 2011a) \\
\hline & Shipping companies announce efforts to help & (Journal of Commerce, 2011s) \\
\hline & Yamato starts bringing supplies on volunteer basis & (Holguín-Veras et al., 2011a) \\
\hline \multirow[t]{4}{*}{$3 / 16 / 2011$} & Express carriers restore service (UPS, FedEx, DHL) & (Journal of Commerce, 2011a) \\
\hline & Passenger airlines cancel flights to Tokyo & (Journal of Commerce, 2011a) \\
\hline & Shortages of critical supplies reported & (New York Times, 2011b) \\
\hline & Destruction of production bases described & (Daily Yumiuri, 2011b) \\
\hline \multirow[t]{5}{*}{$3 / 17 / 2011$} & Shipping lines start to cut down service due to nuclear crisis & (Journal of Commerce, 2011n) \\
\hline & Shift to air transportation noticed & (Journal of Commerce, 2011h) \\
\hline & Hardships in shelters described & (New York Times, 2011c) \\
\hline & Yamato approaches government to offer help & (Holguín-Veras et al., 2011a) \\
\hline & Sendai airport opens & (Washington Post, 2011c) \\
\hline \multirow[t]{8}{*}{$3 / 18 / 2011$} & Port of Sendai opens to relief supplies & (Journal of Commerce, 2011r) \\
\hline & Ships advised to stay clear of Fukushima & (Journal of Commerce, 2011r) \\
\hline & Ocean carriers cancel some services & (Journal of Commerce, 2011p) \\
\hline & Humanitarian crisis increases, only a trickle of supplies & (Washington Post, 2011c) \\
\hline & Government criticized for lack of help & (Daily Yumiuri, 2011a) \\
\hline & SDF announces that will distribute supplies & (Daily Yumiuri, 2011a) \\
\hline & Trucking associations offer help, refused for lack of fuel & (Daily Yumiuri, 2011a) \\
\hline & Sagawa approaches government to offer help & (Holguín-Veras et al., 2011a) \\
\hline \multirow[t]{3}{*}{$3 / 19 / 2011$} & South Korea donates 6,000 blankets & (Kyodo News, 2011c) \\
\hline & Volunteers start work & (Daily Yumiuri, 2011c) \\
\hline & Sagawa starts operations in Ishinomaki and Onagawa & (Holguín-Veras et al., 2011a) \\
\hline \multirow[t]{2}{*}{$3 / 21 / 2011$} & 110,000 blankets donated so far & (Japan Times, 2011a) \\
\hline & Yamato resumes operations DC to DC & (Holguín-Veras et al., 2011a) \\
\hline \multirow[t]{2}{*}{$3 / 22 / 2011$} & Oil tankers arrive at Port of Sendai & (Journal of Commerce, 2011q) \\
\hline & Carrier offers free transport & (Journal of Commerce, 2011o) \\
\hline \multirow[t]{2}{*}{ 3/23/2011 } & Oil tanker arrives at Port of Hachinobe & (Journal of Commerce, 2011e) \\
\hline & Sagawa starts operations in Higashi Matsushima & (Holguín-Veras et al., 2011a) \\
\hline \multirow[t]{3}{*}{$3 / 24 / 2011$} & All ports and airports open & (Journal of Commerce, 2011k) \\
\hline & Yamato starts operations in Minami Sanriku and Kesennuma & (Holguín-Veras et al., 2011a) \\
\hline & Tohoku Motorway opens access to Fukushima Prefecture & (Taniguchi et al., 2011b) \\
\hline \multirow[t]{3}{*}{$3 / 25 / 2011$} & Carrier suspends calls to Tokyo and Yokohama & (Journal of Commerce, 2011f) \\
\hline & Carrier resumes service to Nagoya & (Journal of Commerce, 2011g) \\
\hline & Yamato resumes business/home deliveries outside disaster area & (Holguín-Veras et al., 2011a) \\
\hline \multirow[t]{3}{*}{$3 / 29 / 2011$} & Carrier turned away from China & (Journal of Commerce, 2011b) \\
\hline & 91\% of infrastructure related requests fulfilled & (MLIT, 2011) \\
\hline & Port of Sendai opens to commercial domestic traffic & (Journal of Commerce, 2011l) \\
\hline
\end{tabular}




\begin{tabular}{|c|l|l|}
\hline 4/6/2011 & Supplies reported no matching the needs of survivors & (Japan Times, 2011b) \\
\hline 4/9/2011 & Yamato and Sagawa start getting paid & (Holguín-Veras et al., 2011a) \\
\hline 4/12/2011 & Trucks able to travel to Fukushima (air lift ends) & (Taniguchi et al., 2011b) \\
\hline Mid-April & Private sector supply chains reestablished in Kesennuma & (Holguín-Veras et al., 2011b) \\
\hline
\end{tabular}

Note: SDF refers to Self Defense Force.

As expected in catastrophic events, all participants reported major impacts on their operations (HolguínVeras et al., 2011b; Holguín-Veras et al., 2011d; Taniguchi et al., 2011a; Taniguchi et al., 2011b; Taniguchi et al., 2011c; Taniguchi et al., 2011d). In some cases, public sector staff were killed, injured or missing, and key components of the response system were destroyed. Topping this list is the hospital at Minami-Sanriku, which was hit by tsunami waves so high that only the individuals that made it to the roof of the four story building survived. In all cases, the disaster led to the collapse of power and communication systems, major interruptions of private sector supply chains, and extreme shortages of fuel (in some cases there was no fuel at all, in others there was no power to extract fuel from underground tanks). In contrast with Haiti-where the earthquake killed or injured the local leadership expected to lead the response (Holguín-Veras et al., 2012a) — in most of the cases the local leadership survived, led the response, and provided visible links to the outside help. There were exceptions such as the city of Otsushi, where town leaders gathered to coordinate the response, and died when the waves overtopped the seawall; and Minami-Sanriku, where the senior leaders were killed by the massive tsunami waves that destroyed the town (Holguín-Veras et al., 2011a).

The companies interviewed were also impacted. In the case of the logistic companies 6 out of 69 DCs in Miyagi Prefecture (Yamato), and 3 out of 43 DCs in the entire Tohoku region (Sagawa) were damaged or completely destroyed (Holguín-Veras et al., 2011a). Two DCs and a shopping mall operated by AEON were damaged, and its main DC in Tohoku was without power for a week (Holguín-Veras et al., 2011c). AEON reported a surge in demand-double than in normal conditions-for food and water, which was attributed to precautionary/opportunistic buying as people-particularly in areas that had not suffered major damage-rushed to purchase critical supplies (Holguín-Veras et al., 2011c). In response, numerous retail stores_-sensing a business opportunity-increased the sizes of their orders to take advantage of the situation. This proved to be a major challenge as the main DC in Tohoku did not have power, and was under-staffed as many workers could not find gas to travel to the DC. As a result, the output of the DC was $75 \%$ of its normal amount. This was a major problem because the drop in capacity took place at the very same time when the demand for the supplies dramatically increased. The staff had no experience on how to deal with this a situation like this one.

As soon as they organized themselves, the agencies, prefectures, and cities tried to assess the impacts on their jurisdictions. The MLIT and Miyagi Prefecture used helicopters and planes to inspect roads and critical infrastructure (Holguín-Veras et al., 2011d; Taniguchi et al., 2011d). The MLIT reported making good use of the 1,800 Closed Circuit Television Cameras (CCTVs) part of their state of the art Disaster Control Room (DCR) in Sendai City. The DCR has a disaster mode feature-automatically engaged when a warning is received from the national government-that focuses the CCTVs on pre-defined critical infrastructure (e.g., bridges, tunnels), and enabled the MLIT staff to assess infrastructure conditions at key locations. The DCR is also a multi-agency coordination hub, e.g., it has a permanent representative of the Self Defense Force (SDF), and it is designed to be self-sufficient as it is equipped with emergency generators, food, fuel, and water for a week. 
The city of Ishinomaki could not use the helicopters and planes operated by a local detachment of the SDF because they were destroyed by the tsunami waves (the pilots did not take off once tsunami warnings were issued as established in disaster protocols) (Taniguchi et al., 2011c). In contrast to the MLIT and Miyagi Prefecture-which were able to do air inspections-most agencies did not have an idea about the extent of the impacts on the infrastructure and the population. In some cases, the subsidence of the ground - up to $1.0 \mathrm{~m}$-led to flooding in high tide reduced the effectiveness of air inspections, which had to be repeated (Holguín-Veras et al., 2011b).

Following established procedures, the SDF controlled access to the disaster area (none of the interviewees were directly involved in access control). The interviewees reported that in the first phase, only emergency vehicles were allowed to enter; in the second phase, delivery trucks were granted access; and that finally, all restrictions were lifted. Some respondents indicated that unscrupulous individuals falsely reported transporting supplies to gain entrance to the area and/or to avoid paying the tolls at the Tohoku Motorway, which had waived the tolls for vehicles involved in relief efforts.

Not widely reported in the media is that the PD-HL operations had a very inauspicious start. To start with, prefectures and cities - which had not even identified PD-HL as a critical function in their disaster plans - made no provisions for it. Most likely influenced by their experience with small disasters in which PD-HL is of secondary importance, disaster response planners failed to recognize that catastrophic events require complex PD-HL operations in which most of the relief supplies have to be transported from the outside. Moreover, with hundreds of thousands of individuals needing critical supplies PD-HL became a monumental challenge for which cities, prefectures, as well as the national government, were not ready. As a result, for at least the first six days of the crisis, hundreds of thousands of survivors did not receive relief supplies (Daily Yumiuri, 2011a; Sakurai, 2011). The lack of a government-led PD-HL response prompted heavy criticism of the official response, which was accused of ignoring the plight of the survivors: a member of the Democratic Party of Japan said, “...The prime minister and Mr. Edano [Chief Cabinet Secretary] are focusing too much on the accidents at the nuclear reactors, and not caring enough about the evacuees...” (Daily Yumiuri, 2011a). In response to the heavy criticism-in day seven of the crisis - the SDF announced that it will distribute relief supplies to the individuals that survived the disaster (Daily Yumiuri, 2011a). The crisis would have been much worse, if not by the admirable community spirit of the Japanese that led them to share the supplies they had with their neighbors, as corroborated by the first author in Higashi-Matsushima (Holguín-Veras, 2011). In spite of that, the human suffering due to the lack of critical supplies was significant, though it did not lead to widespread riots. However, the interviewees reported that warehouses in the Watanoha district of Ishinomaki were broken into to get supplies, and that 40 million Yens were stolen from a bank (Holguín-Veras et al., 2011a). At this critical juncture, everything seemed to indicate that—with the SDF strained to the limit —and the normal private sector supply chains severed, that a huge humanitarian crisis was unavoidable.

Fortunately, fate intervened in the form of a handful of trucking/distribution companies (e.g., Yamato, Sagawa, Nittsu, and Akabo) that-because of their role in the food and retail sectors-were in a position to know that the private sector supply chains had been severely disrupted, and that the public sector was not ready to fill the gap. They recognized that a huge humanitarian crisis was underway and that without their intervention things would get much worse. Independently of each other, they approached local officials during the period March $15^{\text {th }}-19^{\text {th }}$ and took the unprecedented step of volunteering to do local deliveries of relief aid (Holguín-Veras et al., 2011a). In the two cases interviewed for this paper (i.e., Yamato and Sagawa), the companies paid for the costs of the local distribution and the supplies that they 
distributed during the first week; and the costs (except fuel) of the hundreds of trucks and drivers that they volunteered for almost a month of PD-HL operations in entire cities (Holguín-Veras et al., 2011a). Without their timely intervention — and the assets, expertise, and supplies they brought with them — the situation in Tohoku would have taken the path of Haiti, where the lack of help from the local business class contributed to a crisis of huge proportions (Holguín-Veras et al., 2012a). Ironically, many other trucking associations and companies seemed to have volunteered their services, though their offers were rejected because the government could not guarantee the fuel for the return trips (Daily Yumiuri, 2011a). Although it is not the authors' objective to second guess decisions made in the midst of chaotic field conditions, it is important to highlight that using SDF's assets to transport fuel to the disaster area would have enabled the government to accept the help from the private sector, thus expediting the relief effort. This point was made by an anonymous source that told the Japanese media that "Giving these firms preferential access to fuel would be one way to help us get more aid on the road to Tohoku,"..." There isn't a lack of supplies." (Daily Yumiuri, 2011a).

These volunteer companies had a very hard time conducting their improvised PD-HL operations, notwithstanding their high level of professionalism, experience, and the fact that at least one of them (Sagawa) stated that they “...learned from the 1995 Kobe earthquake experience...”. In most cases it took the companies more than a week to start distributing supplies to the RCs, which began in earnest at the end of the period March $19^{\text {th }}-25^{\text {th }}$, 2011. The staff reported being shocked and overwhelmed by the complexity and magnitude of the challenge. Unanimously, they complained about: not having a good idea about the actual needs at the RCs, not knowing the conditions of roads and bridges, the lack of a single person in command of the PD-HL effort, and above all, of the challenge of doing local deliveries in a disaster zone. In their own words: “...transporting to DCs was easy...”, while “...transporting to RCs was very difficult...” (Holguín-Veras et al., 2011a). The experience of these world class companies clearly show that the local distribution of critical supplies cannot be taken for granted; and that the response plans for catastrophic events must seriously take into account, and prepare for, such challenging effort.

An even more challenging scenario was presented to the leaders of Fukushima Prefecture. To start with, the nuclear crisis deterred the flow of volunteers and supplies to areas within a large radius around the nuclear plants due to concerns of radiation exposure. Thus, local responders were left to their own devices and the help they could get from the overextended SDF. Although there are no hard data, there is substantial evidence that suggests a significant deterrence effect. For instance, in the days after the crisis started airlines canceled numerous flights to Northern Japan and Tokyo (Journal of Commerce, 2011a), major shipping companies rerouted their ship schedules to avoid nuclear contamination (Journal of Commerce, 2011n; Journal of Commerce, 2011i; Journal of Commerce, 2011f), and even the U.S. Navy ships pulled out of the area due to the radiation risk (Reuters, 2011). However, in contrast to other areas where infrastructure had been devastated, most roads were passable.

Thus, the Fukushima Prefecture had a very difficult time mounting the relief effort (Taniguchi et al., 2011b). The most significant of the impacts on the PD-HL effort was that countless truckers decided to stay away from the entire prefecture thus reducing the flow of supplies, similar to what was observed after Hurricane Katrina when truckers abandoned the relief effort upon hearing that a second hurricane was coming (Holguín-Veras et al., 2007). The staff indicated that “...a large number...” of truckers simply unloaded their cargo at the border of Fukushima Prefecture, at about $80 \mathrm{~km}$ from the city of Fukushima (e.g., at Koriyama and Azaka Kawamachi) or simply parked the trucks and left, even though their destinations were well outside the exclusion zone. Of great significance was the case of 36 fuel tankers 
that — at the height of the crisis—-were left about $50 \mathrm{~km}$ from their destination, which required sending drivers to retrieve the trucks and their critical cargo (Taniguchi et al., 2011b).

Furthermore, the nuclear crisis led to a situation in which almost all supplies had to be transported by plane to the Fukushima Airport. This was because: (1) of the variability of travel times could lead to potentially long exposures (the closing of the Tohoku Motorway until March $24^{\text {th }}$ led to great uncertainty about travel times in the network); and, (2) planes have relatively short exposure times as they could quickly enter and leave the area. At the beginning, only official planes were allowed to land as there were no resources to sort donations. Planes were the main form of transportation until April 12 $2^{\text {th }}$, 2001 when all highways were finally opened.

The PD-HL operations were further complicated by the orders issued by the Japanese government to minimize nuclear exposure, which had different effects on the populations in the areas surrounding the nuclear plants. More specifically, large numbers of people had to relocate elsewhere, while others were asked to stay indoors (including those living in areas impacted by the earthquake and tsunami). The Fukushima prefecture staff reported that, in spite that the national government had instituted a $20 \mathrm{~km}$ exclusion zone with a mandatory evacuation, and another zone between 20-30 km where people could leave but not return, many individuals stayed on both. For that reason, the prefecture asked Tokyo Electric Power and SDF to distribute supplies on their behalf. The suffering of those that stayed behind is dramatically illustrated in the video uploaded to the Internet by the mayor of Minami-Soma (Sakurai, 2011). In the video, he explains how the nuclear crisis both forced the survivors indoor, and prevented the arrival of the volunteers and supplies they needed. Specifically, he asked help from volunteers willing to “...act at their own risk...” that “...could bring in petrol (so that they could leave)...”. He implied that large numbers of residents, that stayed indoors to avoid nuclear contamination, could not leave because of lack of fuel and vehicles and the impassable roads, and were not receiving the supplies needed.

The Tohoku experience yet again demonstrated the problems caused by excessive donations of non/low priority goods. This phenomenon, i.e., material convergence (Fritz and Mathewson, 1957), has been identified in all large disasters and labeled as a “...second tier disaster...” (Newsweek, 2002). The convergence of non/low-priority goods is extremely problematic as it arrives in very large volumes and at a time at which the responders are busy with other more important activities, disrupting operations. The trucking companies interviewed-which were responsible for the operations of the DCs and had to deal with the problem — estimated that between 50\% and 70\% of the cargo handled was not needed at all and should not have been sent there (Holguín-Veras et al., 2011a). This is consistent with the literature on the subject that suggest 60\% (Fritz and Mathewson, 1957), and with the observations of the first author on the Katrina and Haiti disasters (Holguín-Veras et al., 2007; Holguín-Veras et al., 2012a). The amount of resources required to manage this massive and uncoordinated flow of goods is significant. As an illustration, when the authors visited the Iwate Industry and Culture Convention Center in Iwate Prefecture, one third of the staff (20 out of 60 workers) were sorting the unnecessary clothing that had been donated that was occupying about $40 \%-50 \%$ of the floor space. The consensus was that blankets, clothing (both used and new), and water were the top three non/low priority supplies. The case of blankets is illustrative of the dynamic nature of priorities as during the first week of the response they were highpriority because of the prevailing cold weather. However, as the weather warmed up, blankets ceased to be high-priority and became a nuisance as hundreds of thousands of them-donated by other prefectures, and countries like Canada (25,000 blankets) and South Korea (6,000 blankets)—descended on Tohoku (Kyodo News, 2011a; Kyodo News, 2011c) complicating the response. For instance, the Iwate Industry 
and Culture Convention Center had 100,000 blankets in excess of the 100,000 that were actually needed. Thus, at least $50 \%$ of the blankets that arrived at Iwate Prefecture were not used at all.

\subsection{Summary statistics}

The experience of prefectures and cities in setting up the PD-HL distribution network provides guidance for disaster planning purposes regarding how many DCs and RCs may be needed in similar operations. To this effect, this section analyzes the structure of the distribution network in relation to the number of internally displace people (IDP) at the peak of the crisis. Table 2 shows the number of DCs, RCs, and IDPs for the prefectures and cities for which data were provided to the authors, together with the average number of IDPs per DC and RC. These estimates represent the average number of IDPs that ultimately depended on a given DC or RC. In the case of the RCs, since many IDPs were staying in cars and abandoned buildings, the average number of IDPs/RC is not necessarily the same as the number of IDPs that stayed at the RC.

Table 2: Number of Distribution Centers, Refuge Centers, and Internally Displaced People

\begin{tabular}{|l|r|r|r|}
\hline A) Prefectures & \multicolumn{1}{|c|}{$\begin{array}{l}\text { Miyagi } \\
\text { Prefecture }\end{array}$} & Iwate Prefecture & $\begin{array}{c}\text { Fukushima } \\
\text { Prefecture }\end{array}$ \\
\hline Key statistics & $2,348,165$ & $1,330,147$ & $2,029,064$ \\
\hline Population Before Disaster & 20 & 13 & 22 \\
\hline Distribution Centers (DCs) & 1,000 & 342 & 350 \\
\hline Refugee Centers (RCs) & 440,000 & 100,000 & 30,000 \\
\hline Internally Displaced People (IDPs) & 22,000 & 292 & 1,364 \\
\hline Average Number of IDPs per DC & 440.00 & 292.40 & 85.71 \\
\hline Average Number of IDPs per RC & & &
\end{tabular}

\begin{tabular}{|l|r|r|r|r|}
\hline B) Cities & \multicolumn{1}{|c|}{ Ishinomaki } & Kesennuma & Onagawa & $\begin{array}{c}\text { Higashi } \\
\text { Matshushima }\end{array}$ \\
\hline Key statistics & 160,826 & 73,489 & 10,390 & 46,412 \\
\hline Population Before Disaster & 19 & 3 & 1 & 2 \\
\hline Distribution Centers (DCs) & 170 & 99 & 17 & 68 \\
\hline Refugee Centers (RCs) & 71,000 & 17,000 & 5,500 & 13,712 \\
\hline Internally Displaced People (IDPs) & 3,737 & 5,667 & 5,500 & 6,856 \\
\hline Average Number of IDPs per DC & 710.00 & 171.72 & 323.53 & 201.65 \\
\hline Average Number of IDPs per RC & & & &
\end{tabular}

The estimates show that, at the prefecture level, there was a wide range of conditions. Miyagi Prefecture had the highest average of IDPs/DC $(22,000)$ and of IDPs/RC (440), while the Fukushima Prefecture had the lowest values. These results make sense as Miyagi Prefecture was the one that experienced the bulk of the physical damage, and the one with the largest population impacted by the disasters. The statistics for individual cities exhibit a narrower range. In terms of the average number of IDPs per DC, Higashi Matsushima had the highest value (6,856 IDPs/DC) and Ishinomaki the lowest (3,737 IDPs/DC). However, in terms of the number of IDPs per RCs, Ishinomaki had the highest value (710 IDPs/RC) reflecting the heavy damage that the city suffered. 
Although the authors did not have access to the number of DCs and RCs that were specified in the disaster response plans, the information gathered for one of the cities indicate that the actual numbers were four times larger than the ones specified in the plan. This clearly illustrates the significant difference in the magnitude of needs between disasters and catastrophes.

\section{LESSONS LEARNED}

The interviews conducted with the participants in PD-HL efforts concluded with questions about the lessons they learned, what they advise others, and what they would do differently based on their experience. Their answers are summarized in Table 3, which shows that the responses are dominated by the perceived inadequacy of the disaster plans, and the importance of putting in place a number of steps to improve communication, coordination, and enhance efficiency of the overall response.

Table 3: Lessons Learned as Stated by the Interviewees

\begin{tabular}{|c|c|c|}
\hline & Key lessons learned: & What to do differently, advise to others: \\
\hline 愳 & $\begin{array}{l}\text { Reality is more difficult than what described } \\
\text { in the disaster plan. Planning for larger } \\
\text { disasters is extremely important. }\end{array}$ & $\begin{array}{l}\text { Communications with local MLIT offices should } \\
\text { have been better. }\end{array}$ \\
\hline 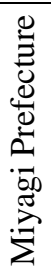 & $\begin{array}{l}\text { The response required resources that they did } \\
\text { not have. Better communication equipment and } \\
\text { helicopters were needed. The importance to } \\
\text { have strong linkages between municipalities } \\
\text { and prefecture. Biggest challenge: perishables } \\
\text { and isolated towns. }\end{array}$ & $\begin{array}{l}\text { To provide subsidies to municipalities so that } \\
\text { they purchase satellite phones. }\end{array}$ \\
\hline 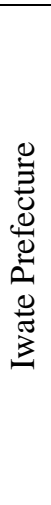 & $\begin{array}{l}\text { The importance of: (1) adjusting to } \\
\text { conditions, e.g., allowing the person in charge } \\
\text { of a DC to decide without consulting superiors } \\
\text { worked well; (2) establishing a relationship } \\
\text { with logistic companies before the disaster, } \\
\text { (too difficult to do it after); (3) unified } \\
\text { command at DCs, e.g., having two groups } \\
\text { doing distribution and inventory management } \\
\text { caused problems; and, (4) female teams to } \\
\text { assess needs of female IDPs (men-only teams } \\
\text { did not work well). }\end{array}$ & $\begin{array}{l}\text { There should be only one person in charge of } \\
\text { humanitarian logistics, with the power and } \\
\text { financial resources to do what is needed. One } \\
\text { important thing that the national government } \\
\text { should do is to help pay for the expenses. Create } \\
\text { female teams to assess the needs of women. }\end{array}$ \\
\hline 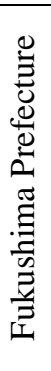 & $\begin{array}{l}\text { The importance of: (1) using the right type of } \\
\text { trucks ( } 2 \text { t trucks are best); (2) providing } \\
\text { psychological assistance to IDPs; (3) using } \\
\text { helicopters for search and rescue, and } \\
\text { transporting supplies to isolated places; and, (4) } \\
\text { responding within 3-7 days. Google Earth and } \\
\text { ITS-Japan helped with satellite pictures and } \\
\text { information about road conditions. }\end{array}$ & $\begin{array}{l}\text { Recognize the importance of evacuation and } \\
\text { provision of information. Assess bridge conditions } \\
\text { with inspectors. Take advantage of satellite } \\
\text { imaging to assess infrastructure conditions. Try to } \\
\text { get satellite pictures sooner. }\end{array}$ \\
\hline
\end{tabular}




\begin{tabular}{|c|c|c|}
\hline 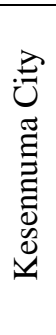 & $\begin{array}{l}\text { "Everything." Disaster plan did not work as it } \\
\text { assumed that only part of the city would be } \\
\text { damaged (the entire city was destroyed). The } \\
\text { basic assumption was wrong. The importance } \\
\text { of satellite phones. Did not have equipment, } \\
\text { electricity, phones. Had to do basic things (e.g., } \\
\text { receiving, storage, distribution by hand). }\end{array}$ & $\begin{array}{l}\text { Emphasize humanitarian logistics, which is not } \\
\text { considered in disaster planning. }\end{array}$ \\
\hline 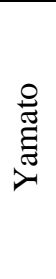 & $\begin{array}{l}\text { Gap between demand and supply } \\
\text { dynamically changed. Government must have } \\
\text { closed it sooner. Clothing donations were a } \\
\text { problem (too difficult to match to survivors). } \\
\text { The level of priority of supplies changes with } \\
\text { time. }\end{array}$ & $\begin{array}{l}\text { To prepare good response plans. To find ways to } \\
\text { accurately estimate the needs based on lifestyle } \\
\text { and community habits. Government should engage } \\
\text { the private sector sooner. }\end{array}$ \\
\hline 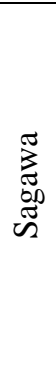 & $\begin{array}{l}\text { Lack of planning for private-public work led } \\
\text { to problems. Military forces collaborated really } \\
\text { well. SDF did not collaborate well with cities, } \\
\text { though it did a very good job delivering } \\
\text { supplies to isolated places. The difficulty of } \\
\text { local distribution: “...long haul was OK, but } \\
\text { distribution from DC to RCs was very difficult, } \\
\text { we need more planning and coordination...” }\end{array}$ & $\begin{array}{l}\text { To put someone in control, “...nobody in control } \\
\text { of who delivers to the people in need...” Improve } \\
\text { agreements between prefectures and JTA so that } \\
\text { they include local distribution. Need to reduce the } \\
\text { excessive reliance on SDF which only delivers } \\
\text { basic supplies and has a lot of problems because } \\
\text { their vehicles (troop carriers) are not designed for } \\
\text { logistic duties. }\end{array}$ \\
\hline 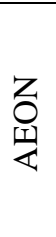 & $\begin{array}{l}\text { Importance of emergency generators. That } \\
\text { they could work without computers, power, and } \\
\text { technology. Gained experience with other mo- } \\
\text { des. The importance of setting up a command } \\
\text { center quickly, and prepare rations for IDPs. }\end{array}$ & $\begin{array}{l}\text { They would try to have control on the total flow } \\
\text { of cargo. Store owners ordered supplies without } \\
\text { considering the entire picture. Install emergency } \\
\text { generators. }\end{array}$ \\
\hline
\end{tabular}

Not included in Table 3 are the statements provided by some of the staff of the private companies interviewed, which were critical of some aspects of the official response. Due to the importance and sensitive nature of the comments, the authors decided to discuss them without attribution to any specific company. Central to their criticism is the lack of an adequate process to either phase out their involvement as volunteers, or transition their services to a for pay basis. As indicated before, the companies became involved as volunteers which they had not planned for. At some point in the response, when they told government officials that they could not continue paying for the costs of the distribution effort, they were advised to try to get contracts with the cities (which were in dire financial straits, had been directly impacted by the disaster, and did not have the administrative structures required to issue contracts). This puts the companies in a quandary as they could not keep absorbing the delivery costs indefinitely, nor they could risk their reputations and simply abandon the relief effort without a viable alternative to replace them. They deemed this decision “...very cruel...”. After considerable wrangling, about a month after starting as volunteers, they were hired by the prefectures to distribute relief supplies. This experience, in which the companies felt were in lose-lose situation, taught them that they need to be careful when deciding to participate in future disaster efforts. In their opinion, a change in mindset is needed as the government "...expects volunteers to do the relief effort..." and companies could only do so much without getting paid. Needless to say, this is very unfortunate as it was the generous efforts of 
these companies what prevented a huge humanitarian crisis. In the opinion of the authors, these companies should be commended for their valiant efforts on behalf of the survivors.

The companies also reported to have problems dealing with what they deemed “...a bureaucratic mindset..." and the desire of some local governments that they distribute the supplies solely on their spheres of responsibility. The case of a hospital that needed relief supplies-but was not the responsibility of a local government-was mentioned. According to the staff, the hospital did not receive the supplies needed because that local government did not allow the company to supply the hospital (in spite of the protestations of the company staff that deemed the decision unsound). It is important to take steps to ensure that this does not happen in the future.

\section{FACTORS THAT EXPLAIN THE CONTRASTING PERFORMANCES OF CONSTRUCTION AND PD-HL OPERATIONS}

As established in the paper, the PD-HL operations faced numerous challenges stemming, in part, from the fact that the disaster response plans only consider small disasters and not a catastrophic event. In contrast, the construction operations (e.g., road opening, physical repairs) were conducted with extraordinary speed and efficiency, in spite of the fact that the corresponding response plan also considered a small disaster.

The performance of construction operations offered a dramatic contrast to PD-HL. Almost immediately after the tsunami, the MLIT promptly decided that the main priority would be to open the East-West arterials that connect the Tohoku Motorway to the coastal areas to the East (hence the name "Comb Operation”). To this effect, the MLIT called on the construction companies under contract and charged them to clear the roads by pushing debris out of the way. By the next day (March 12 $\left.2^{\text {th }}, 2011\right) 11$ out of the 16 arterials roads connecting the Tohoku Motorway to the Sendai East Motorway had been re-opened. This operation, a joint effort with SDF, was successfully completed one week after the tsunami (MLIT, 2011). Both MLIT and SDF brought temporary bridges and boats to expedite the response. In essence, two important response functions, PD-HL and constructions operations, exhibited radically different levels of performance: one did poorly (PD-HL), while the other performed magnificently (construction operations). Understanding the reasons that explain these differences could shed light into the factors that ought to be fostered by public policy. In identifying these success factors, there are two main aspects to be considered: (1) the differences in nature and magnitude of the needs associated with the response to disaster and catastrophes; and, (2) the extent to which a response function, originally designed for a disaster, could be scaled up to respond to a catastrophe. The former aspect represents the demands that the response functions are supposed to fulfill, while the latter describes the supply that the response function delivers. To characterize these aspects, the authors identified the eight factors listed in Table 4, and provided a side by side comparison between the MLIT and the typical situation in prefectures and cities. The factors are grouped in: needs (demand), technical capabilities of the performing units, and interfaces with other key stakeholders.

The first key factor is the need that the activity is expected to fulfill. In the case of the MLIT, the nature of road openings and construction repairs-which was their main charge-is essentially the same in disasters and catastrophes, though the amount of work and criticality are much larger in the latter. For that reason, the response procedures designed with a disaster in mind translated well into the catastrophic case as increasing equipment and manpower accelerated the completion of the task. In contrast, the PD-HL 
operations required after the Tohoku disasters were very different from the ones for a small disaster. The reason is that in the latter, the local distribution of critical supplies does not require sophisticated planning and execution as in most cases only a handful of points of distribution, and a relatively small number of volunteers could cover the needs for the impacted area. Moreover, due to the relatively small size of the impacted area, the best location for the points of distributions is frequently obvious. After a large catastrophe, however, where the PD-HL operations have to satisfy the needs of hundreds of thousands of individuals over larger areas, elaborate plans with hundreds of points of distribution and huge amounts of manpower are needed, as the case of Haiti demonstrated (Holguín-Veras et al., 2012a). Thus, scaling up the PD-HL operations designed for a small disaster only increases the flow of supplies to DCs, and does not solve the local distribution problem (as the disaster plans do not even consider it). The result is paralyzing congestion at the DCs and entry points to the disaster area-because the supplies arrive at the DCs and cannot be distributed forward-as it happened in Haiti (Holguín-Veras et al., 2012a). The chief insight is that the PD-HL operations did not scale up to the catastrophic case because the nature of the job was very different. This was promptly recognized by the responders, which quickly abandoned the original disaster plans.

Table 4: Structural Factors Explaining Performance of Public-Private Joint Work

\begin{tabular}{|c|c|c|}
\hline Factor: & $\begin{array}{c}\text { MLITT (construction repairs, road } \\
\text { opening, debris removal) }\end{array}$ & $\begin{array}{c}\text { Prefectures and cities (post-disaster } \\
\text { humanitarian logistics) }\end{array}$ \\
\hline \multicolumn{3}{|l|}{ Needs } \\
\hline $\begin{array}{l}\text { Nature of the task to the performed in } \\
\text { disasters vs catastrophes }\end{array}$ & $\begin{array}{l}\text { Very similar nature, though in much } \\
\text { larger amounts in catastrophes }\end{array}$ & $\begin{array}{l}\text { Different: disasters do not require } \\
\text { complex PD-HL, catastrophes do }\end{array}$ \\
\hline \multicolumn{3}{|l|}{ Technical capabilities } \\
\hline $\begin{array}{l}\text { Public sector's level of technical } \\
\text { familiarity with the task }\end{array}$ & High & Low/non \\
\hline Jurisdiction of public sector agency & Regional & Local (prefectures or cities) \\
\hline $\begin{array}{l}\text { Private sector's level of technical } \\
\text { familiarity with the task }\end{array}$ & High & $\begin{array}{l}\text { High with commercial logistics, only a } \\
\text { basic idea of PD-HL }\end{array}$ \\
\hline \multicolumn{3}{|l|}{ Interfaces } \\
\hline $\begin{array}{l}\text { Nature of the cooperation agreements } \\
\text { with private sector }\end{array}$ & Specific & Vague \\
\hline $\begin{array}{l}\text { Public sector's ability to integrate and } \\
\text { coordinate outside help }\end{array}$ & High & Low/non \\
\hline $\begin{array}{l}\text { Linkages to the private sector and } \\
\text { other sectors of the civic society }\end{array}$ & $\begin{array}{l}\text { Many and strong (particularly with } \\
\text { construction companies) }\end{array}$ & $\begin{array}{c}\text { Few and weak (particularly with } \\
\text { logistic companies) }\end{array}$ \\
\hline Need for supporting social networks & None & High \\
\hline
\end{tabular}

In terms of the ability of the performing units to deliver the goods/services required, there are major differences. In the case of the MLIT, the technical staff (mostly engineers) is very familiar with construction operations as this is the main core of their work, which they perform on a daily basis. Moreover, since the MLIT staff has a lot of experience coordinating multiple contractors—which they do on a routine basis - the MLIT had a large capacity to integrate outside help during the response. They were also aided by the fact that construction repairs is a highly standardized activity with pre-established construction codes and procedures, which leads to a situation in which construction companies could be 
assigned to almost any job and be expected to deliver a quality result. This, together with contacts with numerous qualified contractors and established and strong internal relations across the MLIT structure, enabled the MLIT to allocate construction work to companies for maximum effectiveness of the overall effort. In addition, MLIT's regional jurisdiction enabled it to have access to resources outside the disaster area, which increased their ability to effectively respond. Equally significant is that construction work is an almost self-contained activity that could take place with minimal help from outside groups, which reduces the need for coordination with other stakeholders.

In contrast, prefectures and cities did not have institutional expertise on PD-HL, had jurisdiction over much smaller areas with lesser resources than a region, did not have strong ties with the private sector companies that could help with the PD-HL effort, and did not possess experience conducting or coordinating PD-HL. Moreover, since PD-HL is not a routine activity for the private sector they need time to adapt before they are fully cognizant of the unique aspects of the work. Another important difference is that in order to conduct successful PD-HL operations, support from a local social network is needed to organize the population, split and distribute the rations. Faced with a multi-jurisdictional disaster that required a massive amount of coordination and knowhow, that they could not do on their own nor were able to get from outside partners, it should not come to a surprise that prefectures and cities did not do as well as the MLIT. In essence, prefectures and cities were structurally hampered to do an efficient PD-HL. Of great significance is that the situation faced by the Japanese prefectures and cities is no significantly different than the ones observed in other parts of the world. In fact, it could be argued that the Japanese are better prepared than most on account of the disaster drills they had, and the agreements with construction and logistic companies (most cities in other parts of the world have not had undertaken such steps). It seems clear that addressing this structural deficiency is needed to ensure that the public sector could fulfill its PD-HL mission. How to accomplish this goal is the objective of Section 7.

\section{POLICY IMPLICATIONS}

The PD-HL response to the Tohoku disaster provides important lessons for disaster preparedness and response, which should be considered for implementation by the agencies involved in disaster preparation and response procedures. This section summarizes the key ones, and puts forward a set of policy recommendations. To facilitate the analyses, the key lessons have been summarized as follows:

(i) The disaster plans failed to consider and prepare for worst case scenarios as they only focused on small events that could be handled by a given public sector agency.

(ii) Not having disaster plans that, in detail, considered post-disaster humanitarian logistic (PD-HL) operations hampered public sector response as local officials had to confront the crisis without any guidance about how to proceed.

(iii) The lack of designated local leaders with primary responsibility for PD-HL and with strong linkages to the logistic industry produced numerous problems. Companies and individuals interested in supporting the PD-HL operations did not know whom to contact to offer help and coordinate efforts; neither the city leaders of the emergent PD-HL response knew whom to contact in the logistic industry to get the help so urgently needed.

(iv) The private sector in the construction, transportation, and retail sectors played a key role as they brought to bear expertise and assets that benefited the response. However, the participation of transportation and logistic companies was improvised, unanticipated, and at times refused. 
(v) The most challenging part of the entire PD-HL process was, by far, the local distribution.

(vi) The lack of training and realistic exercises on PD-HL significantly diminished the effectiveness of the response to the disaster. Among the 60 individuals that were interviewed, only about ten had experience in commercial logistics, and none had any previous exposure to PD-HL.

(vii) The unavailability of technologies and systems to quickly assess the conditions of the transportation network and other critical infrastructures hampered the response.

(viii) The availability of multi-modal transportation alternatives was successfully exploited to transport critical supplies to the disaster area.

(ix) The lack of efficient communications with the field was a negative factor that difficulted the assessment of needs.

(x) The bulk of the relief supplies had to be transported from the outside of the impacted area, as expected in the response to catastrophic events.

(xi) Lack of fuel for the return trips prevented the volunteer participation of numerous trucking companies during the initial days of the crisis.

(xii) The large flow of non/low priority donations created numerous problems as it consumed significant amounts of resources, were not needed, and arrived at a time at which there were more important activities to undertake.

(xiii) Precautionary/opportunistic buying of critical supplies by individuals outside the disaster area aggravated the PD-HL challenge because it prevented the use of those supplies for the benefit of the survivors in the disaster area.

(xiv) The lack of GPS devices in some of the delivery trucks delayed the response as it required the use of local guides that knew how to navigate the impacted area.

These findings provide the basis for a number of policy recommendations that, in the opinion of the authors, could play a key role in improving PD-HL response to future events. A central element of these recommendations is the goal of ensuring scalability of the PD-HL operations as this may be the only way to ensure robustness of the disaster response plans. These recommendations are discussed next.

\section{Recommendation \#1: Create a Logistic Committee to Integrate Civic Society in the Effort}

As outlined in lessons (i) thru (vi), many of the problems encounters in the response were the result of the lack of familiarity with the unique demands that a catastrophic event imposes on PD-HL efforts, and the lack of resources needed to confront the crisis. This insight, together with the analyses of the factors that explain the performance of the construction sector response, suggests the convenience of integrating key representatives of the civic society and the logistic industry-and particularly those involved in the distribution of food, water, medicines, and other supplies likely to become critical after a disaster-to help lead the local PD-HL effort. As part of this concept, a committee of representatives of disaster response agencies, key private sector companies, trade associations, community groups, churches, and any other group that could contribute a large social network, would be trained and certified as PD-HL leaders, and charged with orchestrating the effort in case of a disaster. In essence, these individuals would become part of a "reserve" of post-disaster logisticians that would be called into action if the need arise. This concept is similar to the standard practice in other areas, e.g., medical teams, in which the need to 
incorporate professional help from the outside has long been recognized. It is important for this committee to have a visible presence so that is evident to others outside the group that they are the coordinating hub of the PD-HL effort.

In this context, the incorporation of outside groups and expertise would complement the public sector effort in notable ways because it will: (1) enable logistic professionals with deep knowledge of local conditions to lead the effort; (2) provide access to regional private sector logistic networks that extend beyond the jurisdiction of the public sector agency; (3) contribute connections to the rest of the private sector expanding the potential pool of assets available; (4) provide the logistic effort with access to the social networks of volunteers that are likely to prove influential in community organizing efforts and local distribution of critical supplies. The latter will address one of the major challenges in PD-HL as organizing the population, splitting and distributing rations, and other related tasks require a significant amount of power (Holguín-Veras et al., 2012a). To this effect, the authors' recommendation is to proactively engage local religious groups, community groups and the like so that they become the backbone of the local distribution effort (Holguín-Veras et al., 2012a). Achieving this could open the door to new paradigms of disaster response through better integration of efforts. Moreover, the incorporation of broad sections of the civil society as part of the disaster planning process would allow them to contribute ideas, and know what may be expected from them in the case of a large disaster.

To provide visible points of contacts, it is advisable that the logistic committee designate one or two individuals as the committee leaders. Moreover, in order to ensure both the physical/mental health of the committee leaders and maximize the effectiveness of the PD-HL efforts, it is important to rotate the leadership out of their duties to give them some rest. (The experience of SDF-where 1/3 of the force is always resting, while the other $2 / 3$ work-clearly shows the benefits of planned periods of rest.) Such periods could also be used to provide participants with psychological counseling to help them cope the traumatic experience.

\section{Recommendation \#2: Design Plans for a Wide Range of Events}

One of the key lessons from the Tohoku experience is that the scalability of a response function cannot be taken for granted. Thus, the key to robust design of disaster plans is to ensure that they are able to perform as expected in a wide range of conditions. To ensure that a given operation is scalable, disaster planners must assess the wide range of needs (from small disasters to large catastrophes) and design scalable response operations, i.e., that could satisfy the needs by adjusting upwards or downwards the input resources to provide the supply of goods/services needed at the site. The dual effort of studying the wide range of needs, and designing the corresponding response functions, in a way that could be seamlessly expanded or contracted to meet the needs in the ground, will ensure that a similar template of action be used in a wide range of scenarios. Equally important is that these plans be specific enough to be of help to responders as they should consider and identify: location of DCs and RCs, alternative arrangements in case that some of these facilities are damaged, staffing arrangements, need for prepositioning of supplies, and the like. Taken together, these recommendations could significantly increase robustness and flexibility of disaster response plans.

\section{Recommendation \#3: Design Plans for Easy Integration of Outside Help}

The complexity and magnitude of the PD-HL efforts-particularly the ones after large disasters and catastrophes - stress the need to engage all segments of society in the response, as this is the only way to minimize human suffering and expedite the path to recovery. However, doing so requires considerable 
planning to avoid duplication of efforts, interference, and all the other problems that arise from lack of coordination; as well as the establishment of clear priorities that ensure maximum effectiveness of the delivery of aid. Achieving this requires, in addition of coordination, a reasonable subdivision of the tasks to be performed, and a minimum level of standardization of individual assignments so that there is agreement on what needs to be done. In the PD-HL case, this may require subdividing a large urban area into smaller districts to be assigned to different relief groups, and providing basic training to ensure that all involved know that to do. There are also important technical details that need to be planned for, e.g., to have an adequate supply of fuel at the site to share it with the companies participating in PD-HL.

\section{Recommendation \#4: Train Potential Participants in PD-HL}

It is important to recognize that PD-HL is a highly technical and complex activity. It stands to reason that if large private companies employ large teams of highly trained professionals to organize their logistics, the more complex PD-HL efforts — which directly impact human suffering — should be granted equal or higher professional status. A significant effort should be undertaken to enhance the technical capabilities of all individuals expected to be involved in a PD-HL effort. As part of this, it is important to:

- Train all likely participants (e.g., local officials, members of the proposed logistic committee including private sector logisticians, leaders of community based social networks), on the basics of PD-HL operations. This must include training on: standards of humanitarian aid, procedures to control material convergence, assessing needs after disasters, estimating impacts on physical infrastructure, team building, and stress management.

- Conduct exercises, both real and simulated (table top), so that all participants develop a sense about what may be expected in a real life scenario.

- Foster, train, and support local and regional social networks - such as the ones created and maintained by religious groups, neighborhood organizations, and the like — so that they are ready to collaborate in the PD-HL effort if the need arises.

\section{Recommendation \#5: Preposition Critical Supplies and Equipment}

As amply illustrated in this paper and established in Holguín-Veras et al. (2012b), in the aftermath of a large disaster or a catastrophe, it is not realistic to expect that local responders could provide a substantial first wave of resources to help survivors. This is the net result of the likely destruction of local inventories and logistic assets, the huge increases in needs, and that the minimal local inventories that characterize modern supply chains are not likely to be enough to satisfy the emergent needs (Holguín-Veras et al., 2012b). The fundamental implication is that the bulk of the critical supplies needed at the site must be brought from the outside of the disaster area. There are two potential sources for such supplies: (1) supplies stored by private sector operators in, or in transit to, regional distribution centers and warehouses; and (2) emergency stocks of critical supplies maintained by disaster response agencies.

In cases, where there is a regional inventory of critical supplies and equipment not likely to be destroyed by a large catastrophic event, such supplies could be counted to be part of the first wave of resources reaching the site, as long as they are located relatively close to the impacted area. However, this would require the establishment of contracts with the corresponding private sector operators to ensure that the supplies could be requisitioned in case of need. In situations where no such regional distribution networks exist, or when the amount of cargo is not enough to provide a first wave of resources, the only alternative is that disaster response agencies preposition critical supplies. It is important to stress that it is not 
advisable to rely on local inventories of critical supplies and equipment as these are susceptible of damage and destruction by the event. The cases of Haiti and Japan made this point abundantly clear.

\section{Recommendation \#6: Control Material Convergence}

The research reported in this paper, yet again, highlighted the problems created by the non/low priority component of the material convergence generated by a large disaster; and the necessity to implement proactive procedures to dampen precautionary/opportunistic buying (Holguín-Veras et al., 2013a). In this context, it is important to: (1) ensure that proper control procedures are in place to allow only high priority supplies to enter the disaster area, divert low priority supplies to secondary DCs in the outskirt of the impacted areas, and refuse/destroy non priority supplies; (2) implement proactive donation management plans that provide potential donors with guidelines about what and when to donate; (3) engage the media so that they convey a realistic representation of needs; and (4) use information systems to try to match needs on the ground to potential donors (Jaller, 2011; Holguín-Veras et al., 2012b; Holguín-Veras et al., 2013a). Regarding the latter, the integration of such information systems for multiple jurisdictions could play the role of a "virtual" pre-positioning of supplies that could make it easier to respond in the case of a large disaster.

\section{Recommendation \#7: Control Precautionary/Opportunistic Buying}

Disaster response agencies must also take steps to ensure that precautionary/opportunistic buying of critical supplies does not deplete stocks of critical supplies in the vicinity of the disaster area, which are the supplies best positioned — for reasons of proximity — to be the first wave of resources reaching the site. It is important to minimize such purchases so that the supplies are available for use by the survivors. Doing so would require to: establish agreements with key private sector vendors to allow the requisition of the critical supplies they may have in stock, educate the population about the need to avoid purchases in excess of needs, engage the private sector so that they help steer supplies to the disaster area, put in place rationing schemes until the situation stabilizes, among other demand management measures.

\section{Recommendation \#8: Foster the Development of Supporting Technologies and Systems}

The experience in the immediate aftermath of the Tohoku disasters unambiguously suggests the need to develop and foster the use of technologies and systems to: support prompt and accurate assessment of needs on the ground, facilitate transportation of the supplies, and ensure efficient communications among disaster responders. Integrated systems that combine satellite imagery, GPS, remote sensing, and geographic information systems to provide local responders with an assessment of infrastructure conditions should be a priority. In the case of GPS devices, their availability could help drivers unfamiliar with local conditions navigate the area even though when information about road conditions is incomplete. These systems must be complemented with proper communication, computer and backup systems, and the assets needed to do local inspections. Ensuring good communication should be a key priority to ensure a timely assessment of the needs on the ground. This may require prepositioning of either satellite phones, or priority phones with preferential access to bandwidth, at strategic locationstogether with appropriate charging mechanisms, e.g., small generators with a supply of fuel—so that they could be quickly deployed and used for extended periods of time. 


\section{CONCLUSIONS}

The research reported in this paper leads to a number of important conclusions that could benefit future disaster response, which should be considered for implementation by the agencies involved in disaster preparation and response procedures. The fact that these findings are consistent with what was observed after other catastrophic events, e.g., Katrina and Haiti, clearly suggests that the policy recommendations made in the paper are robust. Among the similarities, it is important to highlight: the need to bring large amounts of supplies from the outside of the impacted area to satisfy the needs of survivors and the response process; the importance of prepositioning critical supplies; the magnitude and complexity of the PD-HL challenge, and particularly of the local distribution; the necessity to integrate all segments of Society - the civic society, military, public sector, the various strata of the private sector-to ensure the most efficient response permitted by the circumstances; and the need to proactively manage and control the flows of non/low/high priority supplies that accompany large disasters.

A key conclusion is that the failure to design a scalable response able to work well in the worst case scenario, i.e., a catastrophic event, was one of the key reasons that explain the problems found in the PDHL response. The reason for this apparent oversight is related to the inherent differences in the needs to be satisfied after typical disasters and catastrophes, and the asymmetric scalability of the operations. To start with, it is important to highlight that the typical disaster does not require a large and complex PD-HL operation, as only the much larger catastrophes do. Unfortunately, this fact is not well known. Consequently, it is natural for disaster planners to think that the procedures that work relatively well for the typical disaster-which is the case most commonly encountered by most disaster responders-would work well in the response to a catastrophe. Thus, simpler PD-HL for a small disaster-which typically only requires transporting relief supplies to a handful of DCs and RCs-cannot be scaled up to the respond to a catastrophe, as in this case a large and complex local distribution effort with large numbers of points of distribution is required. Thus, there is asymmetric scalability as a PD-HL designed for a catastrophic event can always be scaled down to meet the needs of smaller disasters, though the converse is not true. Moreover, the importance of prepositioning critical supplies and equipment was yet again made evident. The Tohoku case demonstrated this in a convincing way.

The Tohoku disaster provides ample evidence of the importance of providing for the conditions that enable scalability of the operations. The contrasting examples of the performance of the construction and PD-HL are quite illustrative. In the case of the construction sector, the disaster plans scaled up extremely well. The plans for PD-HL did not, and were quickly found inadequate and abandoned. Simply put, the PD-HL response plans prepared for a disaster could not be scaled up to respond to a catastrophe. It is important to understand the reasons that explain these contrasting performances, even though the corresponding response plans, most likely, were designed under similar assumptions of disaster size.

The analyses of the factors that explain the contrasting performances of the construction and PD-HL operations involved indicate that having: access to a regional network of resources and assets, a high level of technical expertise at both the responding agency and the emergent partners from the civic society, strong linkages with numerous and competent potential partners, and high level of capacity to integrate outside help to the response; were some of the factors that allowed the MLIT to successfully scale up construction operations in response to the catastrophe. In contrast, cities and prefectures did not have: access to regional resources to support the PD-HL effort, technical expertise or extensive contacts with potential partners that could provide help, or the technical capacity to coordinate with multiple providers. 
Based on this insight, the paper suggests the creation of a committee comprised of representatives from disaster response agencies, private sector companies in key economic sectors (e.g., food, water, medicine), trade organizations, community and religious groups, that would be trained on PD-HL and be put in charge of PD-HL operations in case of need. The authors expect that these individuals, once properly trained on the specifics of PD-HL, will play an influential role by: contributing their technical expertise, experience, professional connections to regional private sector supply chain networks and assets, and contacts to strategically important social networks, thus increasing the resiliency and efficiency of the response. In addition, the paper suggests that disaster plans: be designed to account for a wide range of events ranging from small disasters to large catastrophes; subdivide the work to be done so that groups of responders could tackle specific areas of need with minimal coordination and overlap; and, strive to standardize the tasks to ensure a minimum level of quality in the work done. Integrating the local social networks part of churches, community groups, and the like, on the local distribution of supplies is very important. This is because these social networks are ideal to do local distribution because they tend to be very large, are well connected, and have a philanthropic interest in helping the people in need.

The research also highlighted the importance of proper and effective donation management and of strategic control of precautionary/opportunistic buying by both households and businesses. The first issue is that, if not controlled, the non/low priority flow of cargo will slowdown high-priority supplies. Preventing this from happening consumes large amounts of resources as non/low priority shipments must be diverted away to prevent the collapse of DCs and entry points to the disaster area. Effective donation management requires a combination of: access control to the disaster area so that non/low priority goods are prevented to enter, or redirected to suitable processing points; public awareness campaigns to educate general public, private and public sector executives about how and what to donate; proactive engagement of the news media; and, information systems to match supply to needs in the ground. The second aspect that needs to be pondered is the need to keep under control precautionary/opportunistic purchasing of critical supplies and equipment, particularly in the areas in the vicinity of the disaster site. The reason is that, though these purchases are a natural human reaction to the concerns about shortages of supplies, they deplete the inventory stocks that for reasons of proximity are best positioned to support the response effort. Addressing this requires the collaboration of private sector vendors, community leaders, and the media, as outlined in the paper.

Based on these findings, the paper puts forward six policy recommendations: (1) integrate civic society in disaster preparedness and response efforts; (2) design plans for a wide range of events ranging from small disaster to catastrophic events; (3) design disaster plans for easy integration of outside help by subdiving potential tasks and striving to standardize the assignments thru training; (4) train potential participants in PD-HL activities and procedures; (5) preposition critical supplies and equipment; (6) control material convergence; (7) control precautionary/opportunistic buying; and, (8) foster the development of the supporting technologies and systems. In the opinion of the authors implementing these recommendations could go a long way towards the development of scalable disaster response plans, able to properly fulfill their mandate in a wide range of events.

Taken together, these conclusions shed light into the lessons that should be incorporated in disaster response plans and operations. In spite of the contributions made in this paper, the reality is that PD-HL is still poorly understood. This unfortunate situation highlights the need for additional field research that helps characterize such complex problems. The knowledge derived from these studies will enable disaster responders to develop adequate procedures for responding to catastrophic events. 


\section{ACKNOWLEDGEMENTS}

This research has been funded by the National Science Foundation's projects: NSF-HSD/DRU 0624083: "Contending with Materiel Convergence"; NSF-RAPID "Field Investigation on Post-Disaster Humanitarian Logistic Practices under Cascading Disasters and a Persistent Threat: The Tohoku Earthquake Disasters”; “Cyber Enabled Discovery System for Advanced Multidisciplinary Study of Humanitarian Logistics for Disaster Response” (NSF-IIS 1124827); and Japan Science and Technology Agency's project: Urgent Funding for International Collaborative Research that arises from Earthquake and Subsequent Tsunami and Nuclear Accidents (J-RAPID) "Collaborative Research on Humanitarian Logistics in Great East Japan Earthquake Disasters.” The support of the National Science Foundation and Japanese Science and Technology Agency is acknowledged and appreciated.

\section{REFERENCES}

Altay, N. and W. G. Green (2006). "OR/MS research in disaster operations management." European Journal of Operational Research 175(1): 475-493.

Beresford, A. and S. Pettit (2009). "Emergency logistics and risk mitigation in Thailand following the Asian tsunami." International Journal of Risk Assessment and Management 13(1): 7-21.

Daily Yumiuri (2011a). 6 days on, govt still looking for aid supply plan. The Daily Yumiuri.

Daily Yumiuri (2011b). Production bases destroyed by quake / Manufacturers' plants, distribution facilities in Tohoku, northern Kanto hit hard. The Daily Yumiuri.

Daily Yumiuri (2011c). Volunteer operations start in hard-hit areas. The Daily Yumiuri.

Fritz, C. E. and J. H. Mathewson (1957) "Convergent Behavior: A Disaster Control Problem. Special Report for the Committee on Disaster Studies." Disaster Study, 9.

Galindo, G. and R. Batta (2013). "Review of recent developments in OR/MS research in disaster operations management." European Journal of Operational Research 230(2): 201-211. http://dx.doi.org/10.1016/j.ejor.2013.01.039

Holguín-Veras, J. (2011). Interview with a local community leader and survivors at a refuge center in Higashi Matsushima. Miyagi Prefecture, Japan.

Holguín-Veras, J., M. Jaller, L. Van Wassenhove, N. Pérez and T. Wachtendorf (2013a). "Material Convergence: An Important and Understudied Disaster Phenomenon." Natural Hazards Review. http://dx.doi.org/10.1061/(ASCE)NH.1527-6996.0000113

Holguín-Veras, J., M. Jaller and T. Wachtendorf (2012a). "Comparative Performance of Alternative Humanitarian Logistic Structures after the Port-au-Prince Earthquake: ACEs, PIEs, and CANs." Transportation Research Part A: Policy and Practice 46(10): 1623-1640. http://dx.doi.org/10.1016/j.tra.2012.08.002

Holguín-Veras, J., M. Jaller, L. N. V. Wassenhove, N. Pérez and T. Wachtendorf (2012b). "On the Unique Features of Post-Disaster Humanitarian Logistics." Journal of Operations Management 30: 494506. http://dx.doi.org/10.1016/j.jom.2012.08.003

Holguín-Veras, J., N. Perez, M. Jaller, L. Destro and T. Wachtendorf (2010). On the Need to Reformulate Humanitarian Logistics Modeling. Poster Presentation at the 89th Transportation Research Board Annual Meeting, Washington, D.C.

Holguín-Veras, J., N. Pérez, M. Jaller, L. N. Van Wassenhove and F. Aros-Vera (2013b). "On the appropriate objective function for post-disaster humanitarian logistics models." Journal of Operations Management 31(5): 262-280. http://dx.doi.org/10.1016/j.jom.2013.06.002

Holguín-Veras, J., N. Pérez, S. Ukkusuri, T. Wachtendorf and B. Brown (2007). "Emergency Logistics Issues Affecting the Response to Katrina: A Synthesis and Preliminary Suggestions for Improvement." Transportation Research Record 2022: 76-82. 
Holguín-Veras, J., E. Taniguchi, K. Oi, R. Thompson, F. Pedroso, K. Yamashita and Y. Yamao (2011a). Interview with executives of trucking companies that participated in the distribution of aid after the Tohoku earthquake. Miyagi Prefecture, Japan.

Holguín-Veras, J., E. Taniguchi, K. Oi, R. Thompson, F. Pedroso, K. Yamashita and Y. Yamao (2011b). Interview with staff of Kesennuma City. Kesennuma City, Japan.

Holguín-Veras, J., E. Taniguchi, K. Oi, R. Thompson, F. Pedroso, K. Yamashita and Y. Yamao (2011c). Interview with staff of staff of a large retail company. Morioka, Japan.

Holguín-Veras, J., E. Taniguchi, K. Oi, R. Thompson, F. Pedroso, K. Yamashita and Y. Yamao (2011d). Interview with staff of the Miyagi Prefecture. Sendai, Japan.

Holguín Veras, J. (2012). Japan's 1,000-year-old warning. Los Angeles Times.

Jaller, M. (2011). Resource Allocation Problems During Disasters: The Cases of Points of Distribution

Planning and Material Convergence Handling. Ph.D., Rensselaer Polytechnic Institute.

Japan Times (2011a). Death toll to exceed 15,000 in Miyagi alone: police chief. The Japan Times.

Japan Times (2011b). Relief workers must adjust quickly. The Japan Times.

Journal of Commerce (2011a). Airlines Pull Tokyo Flights, Express Carriers Restore Operations. The Journal of Commerce.

Journal of Commerce (2011b). China Turns Away MOL Ship for Radiation. The Journal of Commerce.

Journal of Commerce. (2011c). "Container Services Resume at Port of Sendai." Retrieved June 9, 2011, from http://www.joc.com/maritime/container-services-resume-port-sendai.

Journal of Commerce (2011d). Deadly Japan Tsunami Triggers Pacific Warnings. The Journal of Commerce.

Journal of Commerce (2011e). First Tanker Arrives at Port of Hachinohe. The Journal of Commerce.

Journal of Commerce (2011f). German Ocean Carriers Avoid Tokyo, Yokohama. The Journal of Commerce.

Journal of Commerce (2011g). Grand Alliance Resumes Nagoya Service. The Journal of Commerce.

Journal of Commerce (2011h). Japan-US Air Freight Rates Rise as Cargo Space Tightens. The Journal of Commerce.

Journal of Commerce (2011i). Japan Container Ports Face Some Radiation Risk. The Journal of Commerce.

Journal of Commerce (2011j). Japan’s Ports, Airports Operating, Some Ships Damaged. The Journal of Commerce.

Journal of Commerce (2011k). Japanese Ports Reopen. The Journal of Commerce.

Journal of Commerce (2011l). Japanese Restore Transportation Systems. The Journal of Commerce.

Journal of Commerce (2011m). Japanese Shipping Stopped by Earthquake and Tsunami. The Journal of Commerce.

Journal of Commerce (2011n). Maersk Ships to Avoid Japanese Radiation Zone. The Journal of Commerce.

Journal of Commerce (20110). NYK Offers Free Tsunami Aid Transport. The Journal of Commerce.

Journal of Commerce (2011p). Ocean Carriers Cancel More Japan Services. The Journal of Commerce.

Journal of Commerce (2011q). Oil Tankers Arrive at Port of Sendai. The Journal of Commerce.

Journal of Commerce (2011r). Some Japanese Ports Reopen. The Journal of Commerce.

Journal of Commerce (2011s). Transport Operators Mobilize Japan Relief. The Journal of Commerce.

Kovacs, G. and K. M. Spens (2007). "Humanitarian Logistics in Disaster Relief Operations." International Journal of Physical Distribution \& Logistics Management 37(2): 99-114.

Kyodo News (2011a). Blankets from overseas warm freezing quake-tsunami survivors. Kyodo News.

Kyodo News (2011b). Damage from mega quake increasing, death toll feared to top 1,800. Kyodo News.

Kyodo News (2011c). S Korea vows maximum support for quake-hit Japan. Kyodo News.

MLIT. (2011, March 18th, 2011). "Operation COMB Completed Today." from http://www.thr.mlit.go.jp/Bumon/B00097/K00360/taiheiyouokijishinn/kushinoha/kushinoha.pdf.

New York Times (2011a). In Tsunami, Japan’s Seawalls Were No Security. New York Times. New York, New York Times. 
New York Times (2011b). Misery and Uncertainty Fill Up Shelters. The New York Times.

New York Times (2011c). Nearly Half a Million Japanese in Shelters, as Tolls Rise and Foreigners Flee. The New York Times.

Newsweek (2002, February 18th, 2002) "\$75 Million of Stuff." pp. 62-63

NHK World News (2011a). Many take shelter in Tokyo. NHK World News.

NHK World News. (2011b). "Surviving the tsunami." Retrieved July 17, 2011, from http://www.putlocker.com/file/82A171CCE7B826BC\#.

NHK World News (2011c). Tokyo trains to resume service a day after quake. NHK World News.

Pan American Health Organization (2001) "Humanitarian Supply Management and Logistics in the Health Sector."

Picciano, J. (2002). Responding to the Unexpected-Identifying Potential Technologies, Research and Development. National Science Foundation's "Responding to the Unexpected” Workshop, New York City.

Quarantelli, E. L. (2006, November 15, 2010). "Catastrophes are Different from Disasters: Implications for Crisis Planning and Managing drawn from Katrina." Understanding Katrina: Perspectives from the Social Sciences $\quad$ Retrieved November 16, 2010, 2010, from http://understandingkatrina.ssrc.org/Quarantelli/.

Reuters. (2011, March 15, 2011). "U.S. moves to shield forces from Japan radiation risk."

Russell, T. (2005). The Humanitarian Relief Supply Chain: Analysis of the 2004 South East Asia Earthquake and Tsunami. Master of Engineering in Logistics, Massachusetts Institute of Technology.

Sakurai, K. (2011, March 24th, 2011). "SOS from Mayor of Minami Soma City, next to the crippled Fukushima nuclear power plant, Japan." from http://www.youtube.com/watch?v=70ZHQ--cK40.

Tabbara, L. N. (2008). Emergency Relief Logistics: Evaluation of Disaster Response Models. Based on Asian Tsunami Logistics Response.

Taniguchi, E., J. Holguín-Veras, K. Oi, F. Pedroso, R. Thompson, K. Yamashita and Y. Yamao (2011a). Interview with staff of Iwate Prefecture. Morioka, Japan.

Taniguchi, E., J. Holguín-Veras, K. Oi, R. Thompson, F. Pedroso, K. Yamashita and Y. Yamao (2011b). Interview with staff of Fukushima Prefecture. Fukushima Prefecture, Japan.

Taniguchi, E., J. Holguín-Veras, K. Oi, R. Thompson, F. Pedroso, K. Yamashita and Y. Yamao (2011c). Interview with staff of Ishinomaki City. Ishinomaki City, Japan.

Taniguchi, E., J. Holguín-Veras, K. Oi, R. Thompson, F. Pedroso, K. Yamashita and Y. Yamao (2011d). Interview with staff of the Ministry of Land, Infrastructure, Transport and Tourism, Tohoku Regional Bureau. Sendai, Japan.

Wachtendorf, T., B. Brown and J. Holguin-Veras (2010). "Catastrophe Characteristics and Their Impact on Critical Supply Chains: Problematizing Material Convergence and Management Following Hurricane Katrina." (in review).

Washington Post (2011a). Calm in the face of latest disaster, Japanese focus on recovery once again. The Washington Post.

Washington Post (2011b). Japan quake: With two natural disasters and a nuclear emergency, recovery begins. The Washington Post.

Washington Post (2011c). With aid slowed by snow, damage to airports, roads, Japanese fend for themselves after quake. The Washington Post. 